\title{
Sarm1 deletion suppresses TDP-43-linked motor neuron degeneration and cortical spine loss
}

\author{
Matthew A. White ${ }^{1 \dagger}$, Ziqiang Lin ${ }^{1,2 \dagger}$, Eugene Kim³ , Christopher M. Henstridge ${ }^{4}$, Emiliano Pena Altamira', \\ Camille K. Hunt ${ }^{1}$, Ella Burchill ${ }^{1}$, Isobel Callaghan ${ }^{1}$, Andrea Loreto ${ }^{5}$, Heledd Brown-Wright ${ }^{6}$, Richard Mead ${ }^{6}$, \\ Camilla Simmons $^{3}$, Diana Cash ${ }^{3}$, Michael P. Coleman ${ }^{5,7}$ and Jemeen Sreedharan ${ }^{1 *}$ (D)
}

\begin{abstract}
Amyotrophic lateral sclerosis (ALS) is a fatal neurodegenerative condition that primarily affects the motor system and shares many features with frontotemporal dementia (FTD). Evidence suggests that ALS is a 'dying-back' disease, with peripheral denervation and axonal degeneration occurring before loss of motor neuron cell bodies. Distal to a nerve injury, a similar pattern of axonal degeneration can be seen, which is mediated by an active axon destruction mechanism called Wallerian degeneration. Sterile alpha and TIR motif-containing 1 (Sarm 1) is a key gene in the Wallerian pathway and its deletion provides long-term protection against both Wallerian degeneration and Wallerian-like, non-injury induced axonopathy, a retrograde degenerative process that occurs in many neurodegenerative diseases where axonal transport is impaired. Here, we explored whether Sarm1 signalling could be a therapeutic target for ALS by deleting Sarm 1 from a mouse model of ALS-FTD, a TDP-43 ${ }^{\text {Q331K }}$, YFP-H double transgenic mouse. Sarm 1 deletion attenuated motor axon degeneration and neuromuscular junction denervation. Motor neuron cell bodies were also significantly protected. Deletion of Sarm 1 also attenuated loss of layer $V$ pyramidal neuronal dendritic spines in the primary motor cortex. Structural MRI identified the entorhinal cortex as the most significantly atrophic region, and histological studies confirmed a greater loss of neurons in the entorhinal cortex than in the motor cortex, suggesting a prominent FTD-like pattern of neurodegeneration in this transgenic mouse model. Despite the reduction in neuronal degeneration, Sarm 1 deletion did not attenuate age-related behavioural deficits caused by TDP-43 ${ }^{\mathrm{Q} 331 \mathrm{~K}}$. However, Sarm 1 deletion was associated with a significant increase in the viability of male TDP- $43^{\mathrm{Q} 331 \mathrm{~K}}$ mice, suggesting a detrimental role of Wallerian-like pathways in the earliest stages of TDP-43 ${ }^{\mathrm{Q} 331 \mathrm{~K}}$-mediated neurodegeneration. Collectively, these results indicate that anti-SARM1 strategies have therapeutic potential in ALS-FTD.
\end{abstract}

Keywords: Sterile alpha and TIR motif-containing protein 1, Amyotrophic lateral sclerosis, TAR DNA-binding protein 43, Wallerian degeneration, Axonal protection, Dendritic spines

\section{Introduction}

Amyotrophic lateral sclerosis (ALS) is a progressive and ultimately fatal adult motor neuron disease that causes inexorable paralysis of limb, bulbar and respiratory muscles. Patients may also demonstrate cognitive deficits

\footnotetext{
* Correspondence: jemeen.sreedharan@kcl.ac.uk

${ }^{\dagger}$ Matthew A. White and Ziqiang Lin contributed equally to this work.

'Department of Basic and Clinical Neuroscience, The Maurice Wohl Clinical Neuroscience Institute, Institute of Psychiatry, Psychology and Neuroscience (IOPPN), King's College London, London SE5 9RT, UK

Full list of author information is available at the end of the article
}

in keeping with frontotemporal dementia (FTD). Current disease modifying approaches for ALS have only a modest effect on survival and new therapeutic agents are urgently required. Targeting the earliest stages in the neurodegenerative process holds the greatest promise for therapeutic advances.

In ALS, pathological studies demonstrate early peripheral denervation before ventral nerve root or motor neuronal cell body loss suggesting that degeneration starts at the nerve terminal and progresses retrogradely along the axon [20]. Indeed, distal corticospinal tract inflammatory

(c) The Author(s). 2019 Open Access This article is distributed under the terms of the Creative Commons Attribution 4.0 International License (http://creativecommons.org/licenses/by/4.0/), which permits unrestricted use, distribution, and 
changes $[8,37]$ and giant axonal swellings have been detected in spinal cords from ALS patients, suggesting early distal axonal degeneration [15, 53]. Similarly, mutant-SOD1 mice with ALS-like phenotypes exhibit presymptomatic muscle denervation and terminal axonal degeneration before anterior horn cell loss $[20,58]$. Axonal transport also appears to fail early in ALS. This is suggested by accumulation of ubiquitinated proteins, phosphorylated neurofilaments, mitochondria and microtubules in proximal axons and anterior horn cells of ALS patients [83]. Mutations in proteins with axonal functions are linked to ALS, including SMN, dynactin and spatacsin $[14,54]$. Given that the axon constitutes $99.9 \%$ of the volume of a motoneuron and therefore places great metabolic demands on the cell, it is perhaps unsurprising that axonal degeneration can be an early event in ALS, and thus an attractive target for therapeutic intervention.

Almost all ALS and as many as half of FTD cases are characterised by pathological ubiquitinated inclusions of TAR DNA-binding protein $43 \mathrm{kDa}$ (TDP-43) [3, 52]. The identification of mutations of TDP-43 in patients with ALS and FTD demonstrates that TDP-43 plays mechanistic roles in neurodegeneration [2, 7, 39]. Disturbances in TDP-43 homeostasis have been shown to affect axonal function and TDP-43 aggregates may form early within motor axons [10]. Knocking down or overexpressing wild-type or mutant TDP-43 disrupts motor neuron axons and terminal arborisations in flies $[16,42,44]$ and zebrafish [38, 41]. TDP-43 transgenic rodents demonstrate early changes in neuromuscular junction (NMJ) and axonal integrity [65, 73, 81, 85, 87]. TDP-43 also localises within presynaptic vesicles in motoneurons in human spinal cord [62] and in axons in vitro [38]. Furthermore, axonal injury causes striking redistribution of TDP-43 from the nucleus to the cytoplasm and axon [50,63]. Collectively, these results highlight how aberrant homeostasis of TDP-43 can directly impair axonal physiology, potentially causing neurodegeneration.

Given the importance of axon degeneration in ALS, there has been great interest in trying to protect axons and synapses as a therapeutic approach. Following injury to a nerve, typically a cut or crush, the process of Wallerian degeneration ensues, leading to fragmentation of axon fibres distal to the injury site within $72 \mathrm{~h}$. This fragmentation was long thought to be due to loss of trophic support from the cell body [80], but studies of the mutant mouse $\mathrm{Wld}^{S}$ (Wallerian degeneration slow) established Wallerian degeneration as a tightly regulated process separate and distinct from apoptosis of the cell body [46]. While wild-type axons start to degenerate from $36 \mathrm{~h}$ following axotomy, $W l d^{S}$ axons remain intact for weeks and can still conduct action potentials [46]. $W l d^{S}$ encodes a fusion protein with nicotinamide mononucleotide adenylyltransferase 1 (NMNAT1) activity, which compensates for the loss of the axonal NMNAT2 isoform, which has a short half-life and is rapidly depleted from axonal segments distal to the site of injury or when its supply is interrupted for other reasons such as axonal transport deficit [13, 25, 47].

Importantly, screening in Drosophila has identified Wallerian degeneration regulating genes, indicating the presence of an endogenous axonal auto-destruction pathway that is conserved in mammals [51, 55, 84]. The first of these genes to be identified, sterile alpha and TIR motif-containing 1 (encoding Sarm1), acts downstream of NMNAT2 loss to promote axon degeneration following axotomy [24, 26, 45, 55, 79]. In fact, the deletion of Sarm 1 is significantly more protective than $\mathrm{Wld}^{S}$ overexpression in an Nmnat2 depletion model of neurodegeneration as mice age [27]. These observations confirmed that Wallerian degeneration is an active, genetically programmed process that can be potently inhibited.

Evidence to suggest that Wallerian-like processes occur in neurodegenerative diseases comes from recent studies in which the axon outgrowth and regeneration factor Stathmin 2 (also known as SCG10) was found to be downregulated in ALS spinal motor neurons [40, 49]. Loss of Stathmin 2 was previously shown to enhance Wallerian degeneration following axon transection [66]. Furthermore, impaired axonal mitochondrial function, an early pathophysiological event in ALS [67], activates the Wallerian pathway leading to Sarm1-dependent axonal degeneration [72]. Mechanistic studies have also shown, to varying degrees, that axonal protection can be neuroprotective. For example, mice lacking Sarm1 have improved functional outcomes as well as attenuated axonal injury following mild traumatic brain injury [31], while deletion of Sarm1 prevents chemotherapy induced peripheral neuropathy [23]. Wld $d^{S}$ can ameliorate axonopathy in models of Charcot-Marie-Tooth disease, Parkinson's disease and glaucoma $[5,60,61] . W l d^{S}$ is also protective in the progressive motor neuronopathy (pmn) mouse [18]. Although $W l d^{S}$ has little effect on survival in mutant-SOD1 mice, it significantly protects NMJs in young G93A transgenic mice [19, 77]. Studies in C. elegans demonstrate that loss of the Sarm1 homolog Tir-1 suppresses neurodegeneration and delays paralysis induced by mutant TDP-43 [78]. Finally, the human SARM1 locus has also been associated with sporadic ALS risk [22]. Collectively, these observations suggest that Wallerian-like mechanisms could contribute to the neurodegeneration seen in motor neuron diseases, and that depletion of SARM1 could have therapeutic potential in ALS. However, there have been no studies in mammalian models that have investigated a link between Wallerian pathways and TDP-43-mediated neurodegeneration. This is a particularly important 
question as TDP-43 pathology is a hallmark of $98 \%$ of ALS, including sporadic ALS. We therefore sought to determine whether SARM1 signalling could be a therapeutic target in ALS by deleting Sarm1 from a TDP$43^{\mathrm{Q} 331 \mathrm{~K}}$ transgenic mouse model of ALS-FTD. Our results demonstrate that Sarm1 deletion has a neuroprotective effect and leads to both improvements in motor axonal integrity and, importantly, lumbar motor neuron survival.

\section{Materials and methods}

\section{Mouse breeding and maintenance}

High expression hTDP ${ }^{\mathrm{Q} 331 \mathrm{~K}}$ and Sarm1 knock out mice were acquired from Jackson Laboratories and maintained on a C57BL/6Babr background in a $12 \mathrm{~h}$ light/ dark cycle with ad libitum access to food and water. Mice were housed in Tecniplast cages within a clean facility. Individual cages contained environmental enrichment items and group sizes of 2-5 mice were routinely maintained. Transgenic colonies were generated by breeding male mice heterozygous for both Sarm1 deletion and $\mathrm{TDP}^{\mathrm{Q} 331 \mathrm{~K}}$ transgenes with Sarm1 heterozygous or null females. Crosses were designed such that all mice also expressed the Thy1-YFP transgene (see Fig. 1a) (Feng Neuron 2000). Genotyping for the YFP-H, TDP ${ }^{\mathrm{Q} 331 \mathrm{~K}}$ and Sarm1 knockout alleles was performed as described previously $[1,4,26]$. Both male and female mice were used for experimental studies; mouse sex and age are highlighted where appropriate. All animal experiments were performed under the UK animals (Scientific Procedures) Act 1986 Amendment Regulations 2012 on Project Licence 70/7620.

\section{Behavioural testing}

Motor testing was performed using Rotarod on both male and female mice (Ugo Basile, Model 7650, Varese, Italy). At least $24 \mathrm{~h}$ prior to testing mice were first trained for $5 \mathrm{~min}$ at the slowest speed and then $7 \mathrm{~min}$ with acceleration. During testing mice were subjected to 7 min trials with acceleration from 3.5 to $35 \mathrm{rpm}$. In each session mice were tested 3 times with a trial separation of $30 \mathrm{~min}$. The latency to fall (maximum $420 \mathrm{~s}$ ) for each mouse was recorded and mean values for each mouse calculated. An individual mouse recording was excluded if it fell off the rod while moving backwards, accidentally slipped or jumped off at a slow speed. Two consecutive passive rotations were counted as a fall and the time recorded as the end point for that mouse. Mouse weights were recorded immediately after completion of rotarod testing. All testing was conducted by operators who were blind to genotype and in a randomised order.

To assess clasping, male mice were suspended by the base of the tail and observed for 10-15 s. Testing took place immediately following measurement of weight.
Hindlimb clasping was rated from 0 to 4 based on severity: $0=$ hindlimbs splayed outward and away from the abdomen, $1=$ one hindlimb partially retracted inwards towards the abdomen for at least $50 \%$ of the observation period, 2 = both hindlimbs partially retracted inwards towards the abdomen for at least $50 \%$ of the observation period, 3 = one hindlimb fully retracted inwards towards the abdomen for at least $50 \%$ of the observation period 4 $=$ both hindlimbs fully retracted inwards towards the abdomen for at least $50 \%$ of the observation period.

All marble-burying testing was conducted in the morning and blind to genotype on both male and female mice. Cages of size $39.1 \mathrm{~cm} \times 19.9 \mathrm{~cm} \times 16.0 \mathrm{~cm}$ height (Tecniplast) were used. Fresh bedding material (Datesand, grade 6) was placed into each cage to a height of $\sim 6 \mathrm{~cm}$. Ten glass marbles $(1 \mathrm{~cm})$ were placed evenly across the bedding. Ten cages were prepared in a single round. One mouse was placed in each of the cages and the lids replaced. Mice were left undisturbed for $30 \mathrm{~min}$ under white light. Mice were then removed, and the number of marbles buried by at least two thirds was scored. Cages were reset using the same bedding material to test another 10 mice.

\section{Pathological studies}

Unless specified, mice were culled by asphyxiation with $\mathrm{CO}_{2}$ followed by cervical dislocation and tissue extraction. Brains and gastrocnemius muscles of male and female mice were weighed. The tissues were then immersion fixed in $4 \%$ paraformaldehyde (PFA) at $4{ }^{\circ} \mathrm{C}$ for $24-48 \mathrm{~h}$, washed in PBS, cryoprotected in 30\% sucrose in PBS to store at $4{ }^{\circ} \mathrm{C}$. For ex vivo MRI studies animals were anaesthetised and transcardially perfused with PBS followed by a 4\% PFA solution. Heads were removed, scalped and then placed into 4\% PFA for at least $24 \mathrm{~h}$. Heads were subsequently rehydrated in PBS with $0.05 \%$ sodium azide for at least 14 days prior to MRI scanning. For lumbar motor neuron quantification tissues were used following transcardial perfusion as above.

\section{YFP-H motor axon quantification}

Spinal cords were extracted from vertebral columns and L4 ventral nerve roots were carefully dissected from male mice. Following dissection the nerve roots were treated for wholemount fluorescence preparation using Vectashield Mounting Medium (Vector Laboratories) as described previously [6]. Z-stacks of the wholemount YFP-H axons were obtained using a Nikon A1R Confocal Laser Microscope System with a 20x objective. The number of YFP+ axons per roots, axon diameters and percentage of fragmentated axons were then measured using NIS-Elements imaging software blind to genotype. 


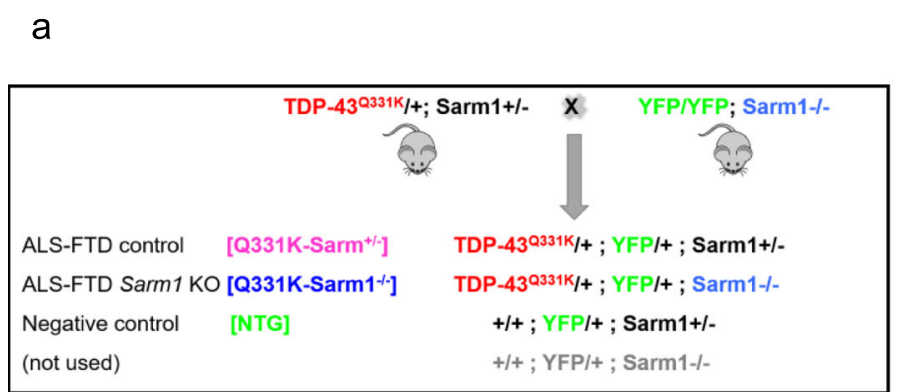
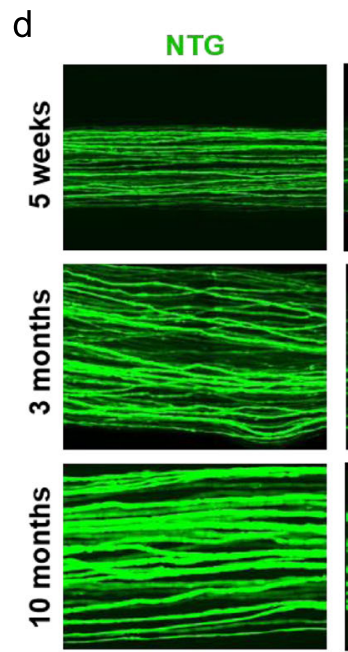

f
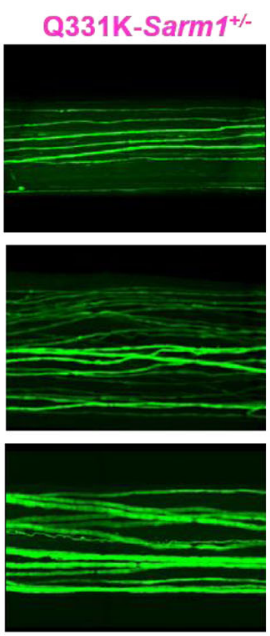

g
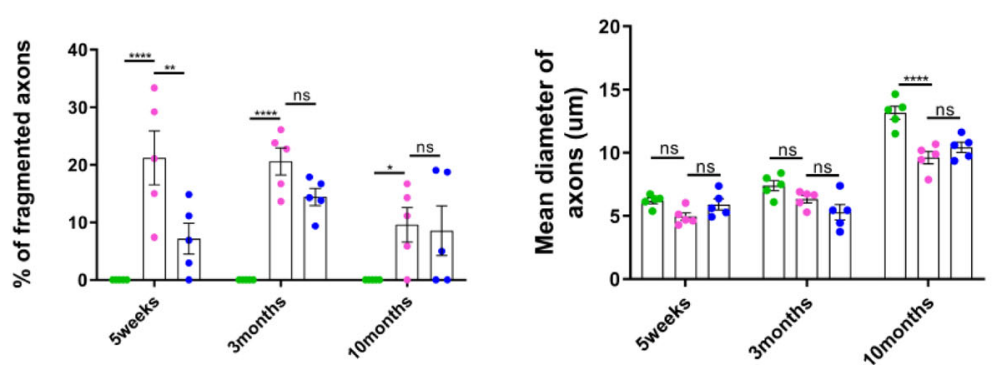

b
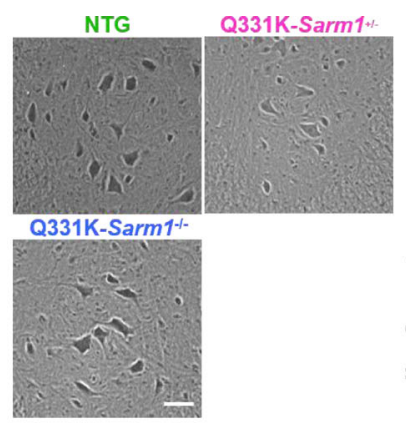

e

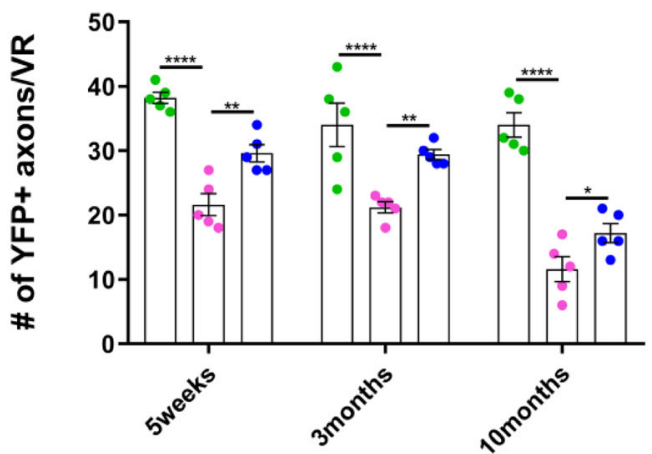

h

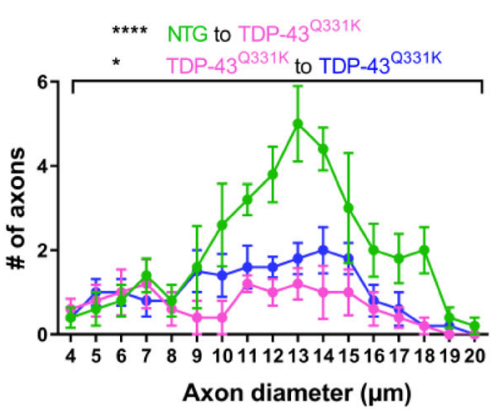

\section{NTg, Sarm1+/- $\square$ TDP-43 ${ }^{\text {Q331K }}$, Sarm1+/= $\square$ TDP-43 ${ }^{\text {Q331K }}$, Sarm1-/-}

Fig. 1 Sarm 1 deletion mitigates TDP43 ${ }^{\mathrm{Q} 331 \mathrm{~K}}$-mediated motor neuron loss and axon degeneration. a. Breeding scheme. b. Nissl-stained lumbar motor neurons of 10-month-old mice. Representative images shown. Scale bar, $50 \mu \mathrm{m}$. c. Quantification of Nissl-stained lumbar motor neurons per section at spinal cord L3. ( $n=4$ NTG; $n=4$ Q331K-Sarm $1^{+/-} ; n=6$ Q331K-Sarm $1^{-1-}$ ) ANOVA $P=0.0404$. Pairwise comparisons: NTG vs. Q331K$\mathrm{Sarm}_{1}^{+/-}$: * $P=0.0351$; Q331 K-Sarm 1 ${ }^{+-}$vs. Q331K-Sarm 1 ${ }^{-1}:$ * $P=0.0392$. d. Representative images showing intact YFP+ axons of $L 4$ ventral roots from mice of three genotypes at different time points. Scale bar $100 \mu \mathrm{m}$. e. Quantification of fluorescent axons in wholemount YFP+ L4 ventral roots at different time points. ANOVA Interaction $P=0.0157$. Pairwise comparisons: 5 weeks, Q331K-Sarm $1^{+/-}$vs. Q331K-Sarm $1^{-1-}: * * *=0.0026 ; 3$

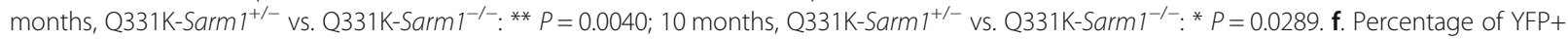
axons undergoing fragmentation in L4 ventral roots at different time points. ANOVA Genotype $P<0.0001$. Pairwise comparisons: 5 weeks, Q331K-

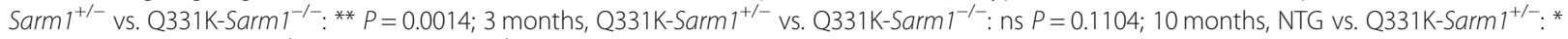
$P=0.0464 ;$ Q331K-Sarm 1 ${ }^{+-}$vs. Q331K-Sarm 1 ${ }^{-1}:$ ns $P=0.7870$. g. Fibre diameters measured at the thickest part of intact YFP+ axons in $L 4$ ventral roots at different time points. ANOVA Interaction $P=0.0051$. Pairwise comparisons: 5 weeks, NTG vs. Q331K-Sarm $1^{+/-}: \mathrm{ns} P=0.1295 ; \mathrm{Q} 331 \mathrm{~K}-$

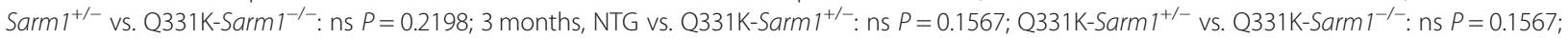
10 months, Q331K-Sarm 1 ${ }^{+--}$vs. Q331K-Sarm 1 ${ }^{-1-}$ : ns $P=0.1810$. h. Distribution of diameters of YFP+ L4 motor axons at 10 months of age. ANOVA Interaction $P=0.0014$. Pairwise comparisons: Q331K-Sarm $1^{+/-}$vs. Q331K-Sarm ${ }^{-1-}:{ }^{*} P=0.0386$. For (e-h) $\left(n=5\right.$ mice per genotype); ${ }^{* * *} P<0.0001$. For (c) one-way (e-h) two-way ANOVA followed by Holm-Sidak post-hoc test for pairwise comparisons. Error bars represent mean \pm s.e.m 


\section{Quantification of neuromuscular junction innervation}

Fixed, cryoprotected gastrocnemius muscles from male mice were placed in a silicone mould with M1 matrix (Thermofisher Scientific), and frozen on dry ice. Longitudinal cryosections $(50 \mu \mathrm{m})$ were mounted onto slides, air dried at room temperature $(\mathrm{R} / \mathrm{T})$ for $5 \mathrm{~min}$ and stored at $-80^{\circ} \mathrm{C}$. To stain neuromuscular junctions (NMJs), slides were brought up to $\mathrm{R} / \mathrm{T}$ and incubated in blocking solution (2\% BSA, $0.5 \%$ Triton X-100, $0.1 \%$ sodium azide) for $1 \mathrm{~h}$. Primary antibodies against $\beta$ IIItubulin (rabbit polyclonal, Sigma T2200) and synaptophysin (mouse monoclonal, Abcam ab8049) were applied at a 1:200 dilution in blocking solution. Sections were incubated at $\mathrm{R} / \mathrm{T}$ overnight. Sections were washed in PBS and incubated for $90 \mathrm{~min}$ with mouse and rabbit Alexa488-conjugated secondary antibodies (Thermofisher Scientific) diluted 1:500 in blocking solution together with TRITC-conjugated alpha bungarotoxin (Sigma, T0195). Z-stacks were obtained using an Olympus Whole Slide Scanner (VS120) with a 20x objective. NMJs from flattened z-stacks of muscle were analysed blind to genotype. Brightness and contrast thresholds were set to optimise the signal-to-noise ratio of the presynaptic staining (anti-tubulin and anti-synaptophysin). To assess the co-localization of pre- and post-synaptic membrane proteins at the NMJ, 90-110 NMJs were analysed per animal per genotype for all ages by eye. Fully innervated NMJs were defined as demonstrating full colocalization of pre- and post- synaptic staining. Fully denervated NMJs were defined as alpha-bungarotoxin signal in the absence of pre-synaptic staining. Partially innervated NMJs were defined as having partial overlap of pre- and post-synaptic labelling.

\section{Spinal cord motor neuron Nissl staining}

Fixed spinal cords from male mice were sub-dissected, paraffin embedded and subsequently sectioned $(10 \mu \mathrm{m}$ thickness) onto charged slides. Sections were initially dewaxed in xylene followed by rehydration through graded alcohols and then washed in water. Sections were stained with cresyl etch violet $(0.05 \%)$ for $30 \mathrm{~min}$, briefly washed in $96 \%$ ethanol, dehydrated in 100\% ethanol, cleared in xylene, mounted (Permount, Fisher) and dried overnight at $\mathrm{R} / \mathrm{T}$. Images were taken on an EVOS FL Cell Imaging System (Thermofisher Scientific) using a $20 x$ objective. For motor neuron quantification, Nissl positive cells of the ventral horn $\geq 20 \mu \mathrm{m}$ in diameter were counted from 7 to 8 sections per mouse to determine the average count per section.

\section{Cortical neuron quantification}

Cyroprotected mouse brains from male mice were embedded and frozen in M1 matrix and sectioned coronally at $60 \mu \mathrm{m}$ thickness on a cryostat (Leica Biosystems).
Sections were then mounted on slides and coverslips applied. Z-stacks were acquired using an Olympus Whole Slide Scanner (VS120) with a 20x objective. Coronal sections from flattened z-stacks of brains were analysed using ImageJ blind to genotype. YFP+ cortical neurons from primary motor cortex and entorhinal cortex were measured from matching sections of each mouse from each genotype. Consistent regions of interest were drawn around the cortex and cells counted using Visiopharm image analysis software (Hoersholm, Denmark).

\section{Cortical dendritic spine analysis}

YFP-H fluorescence was captured using the Nikon iSIM Super Resolution Microscope System running Nikon Elements software using a GFP filter. We focused on the distal branches of the apical dendrites $120 \mu \mathrm{m}$ from the cell bodies of the neurons in layer $\mathrm{V}$ of the motor cortex. To image apical dendritic spines, a 100x oil objective was used to acquire z-plane images with $0.8 \mu \mathrm{m}$ intervals through $20 \mu \mathrm{m}$ of tissue. Five images were collected from the primary motor cortex per animal. To characterise the apical dendritic spines, $\mathrm{z}$-stack images were analysed using Neurolucida Explorer software (MBF Bioscience, USA). Dendrites were traced through stacks with spines marked, and images then exported to Neurolucida Explorer for spine quantification. Branched structure analysis was used to analyse the number of dendritic spines per $\mu \mathrm{m}$ and density of spines of different morphologies. Spines were classified either as mushroom, stubby or thin type according to spine neck length and spine head size, referring to established parameters [30].

\section{Structural magnetic resonance imaging}

Ex vivo, in loco MRI was performed for 10-month-old female mice $(n=32)$ using a $9.4 \mathrm{~T}$ horizontal bore BioSpec 94/20 scanner (Bruker). The mouse heads were placed four at a time in a $50 \mathrm{ml}$ Falcon tube filled with fomblin (Solvay) and scanned overnight using a quadrature birdcage transceiver coil (39 $\mathrm{mm}$ internal diameter). T2-weighted images were acquired using a 3D fast spinecho sequence: effective echo time $30 \mathrm{~ms}$, repetition time $3000 \mathrm{~ms}$, field of view $25 \times 25 \times 20 \mathrm{~mm}$, acquisition matrix $250 \times 250 \times 200$. Diffusion tensor imaging (DTI) data was acquired using a 2D Stejskal-Tanner spin-echo sequence: echo time $22.6 \mathrm{~ms}$, repetition time $4000 \mathrm{~ms}$, field of view $25.6 \times 25.6 \mathrm{~mm}$, acquisition matrix $256 \times$ 256, 67 slices with $0.2 \mathrm{~mm}$ thickness and $0.1 \mathrm{~mm}$ gap, bvalue 1500,30 diffusion directions, 4 b0 images. Fractional anisotropy (FA) maps were computed from the DTI data using dtifit (FSL).

A study-specific template was generated from a subset of 20 mice (antsMultivariateTemplateConstruction2.sh), and all brains were then registered to the template (antsRegistrationSyN.sh). Jacobian determinant maps of 
the deformation matrices were computed and log-transformed to perform voxel-wise nonparametric statistics (FSL randomise, 5000 permutations, threshold-free cluster enhancement) to compare local brain volumes between NTG, Q331K-Sarm1 $1^{+-}$, and Q331K-Sarm1 $1^{-1-}$ mice.

To perform region-of-interest (ROI) analysis, the study-specific template was registered to the DSURQE mouse brain atlas (Mouse Imaging Centre, Toronto), which consists of 28 bilateral and 154 unilateral ROIs (336 total). These labels were transformed to the studyspecific template space, and the volume of each ROI in each mouse was calculated. DSURQE mouse brain atlas can be accessed at: https://wiki.mouseimaging.ca/dis play/MICePub/Mouse+Brain+Atlases\#MouseBrainAtlases-Dorr-Steadman-Ullmann-Richards-Qiu-Egan(40 $\mu \mathrm{m}, \mathrm{DSURQE})$.

\section{Randomisation}

The order and genotype of animals and samples tested was randomized by one operator before subsequent experimental studies were conducted by a second investigator.

\section{Experimental design and statistical analysis}

Experimental data were conducted by researchers blinded to the genotype of animals. Statistical analyses were conducted using Prism 8.1.2 (GraphPad). Graphs were plotted using GraphPad. Use of parametric tests required data to be sampled from a Gaussian distribution. Homogeneity of variance between experimental groups was confirmed by the Browne-Forsythe test for ANOVA. For comparisons between genotypes or experimental groups, one-way or two-way ANOVA was used. Multiple comparisons by ANOVA were corrected using the Holm-Sidak test. All statistical comparisons are based on biological replicates unless stated otherwise. Where technical replication of experiments occurs, this is highlighted in the respective method. Behavioural testing by rotarod and hind limb clasping as well as weight were analysed by Mixed-effects analysis with Geisser-Greenhouse correction followed by Holm-Sidak multiple comparison test. Unless stated otherwise, all charts show mean \pm s.e.m. and statistical tests used are described in the relevant results or figure legends. $P$-values $<0.05$ were considered significant for all statistical analyses used.

\section{Data availability}

The authors will make all data available to readers upon reasonable request.

\section{Results}

Sarm 1 deletion significantly reduces TDP- $43^{\mathrm{Q} 331 \mathrm{~K}}$ mediated motor neuron degeneration

To determine whether Sarm1 deletion could attenuate TDP-43-mediated neurotoxicity we designed a crossing scheme to knock out Sarm1 from a transgenic mouse model of ALS that overexpresses human mutant TDP$43^{\mathrm{Q} 331 \mathrm{~K}}$ under the mouse prion promoter [4]. The cross was designed such that all study mice and littermate controls were also transgenic for YFP-H to facilitate visualisation of central and peripheral neuronal structures $[6,17]$. As Sarm1 $1^{+-}$mice show no significant protection from Wallerian degeneration at $5 \mathrm{~d}$ or more post-lesion [55] we used TDP-43 $3^{\mathrm{Q} 331 \mathrm{~K}}-\mathrm{Sarm}^{+/-}$as controls for TDP- $43^{\mathrm{Q} 331 \mathrm{~K}_{-}}$-Sarm1 $1^{-/}$, so that littermate controls could be used without requiring excessively large breeding numbers (Fig. 1a). The study proceeded using three genotypic groups of mice, analysing males and females separately: TDP- $43^{\mathrm{Q} 331 \mathrm{~K}}$, Sarm $^{+/-}$, YFP-H (hereon referred to as $\mathrm{Q} 331 \mathrm{~K}-$ Sarm1 $^{+/-}$), TDP-43 ${ }^{\mathrm{Q} 331 \mathrm{~K}}$, $\mathrm{Sarm}^{-1-}$, YFP-H (Q331K-Sarm1 $\left.{ }^{-/-}\right)$, and $\mathrm{Sarm1}^{+/-}$, YFP-H mice with no TDP- $43^{\mathrm{Q}^{331 \mathrm{~K}}}$ transgene (NTG).

To examine if Sarm1 deletion significantly reduces TDP-43 ${ }^{\mathrm{Q} 331 \mathrm{~K}}$-mediated motor neuron degeneration, Nissl stained cells of the ventral horn greater than $20 \mu \mathrm{m}$ in diameter were counted (Fig. 1b, c). TDP- $43^{\mathrm{Q} 331 \mathrm{~K}}$ overexpression caused significant motor neuron loss at 10 months of age, reducing numbers by $46 \%$ in Q331K$\mathrm{Sarm}^{+/-}$mice compared to NTG mice $(p=0.0351)$. However, this loss was significantly attenuated in Q331K-Sarm1 $1^{-/}$mice $(p=0.0392)$, which demonstrated $64 \%$ more motor neurons than Q331K-Sarm1 ${ }^{+/-}$mice (only $11 \%$ below the numbers observed in NTG mice). This indicates that Sarm1 deletion significantly reduces motor neuron degeneration caused by TDP $-43^{\mathrm{Q} 331 \mathrm{~K}}$.

\section{Sarm 1 deletion mitigates TDP43 ${ }^{\mathrm{Q} 331 \mathrm{~K}}$-mediated motor axon degeneration}

To examine if enhanced motor neuron survival was also associated with preservation of motor axons, a longitudinal histological evaluation was performed by exploiting the sparse labelling of neurons by YFP-H in L4 ventral nerve roots. Intact and fragmented YFP positive (YFP+) axons within the L4 ventral nerve root were quantified at 5 weeks, 3 months and 10 months of age (Fig. 1d-f). While NTG mice demonstrated 30-40 YFP+ motor axons at all time points, with no axons demonstrating fragmentation, Q331K-Sarm1 ${ }^{+/-}$mice demonstrated only $\sim 20$ YFP+ axons, $\sim 21 \%$ of which were fragmented as early as 5 weeks of age (Fig. 1e, f). Furthermore, the number of intact axons in Q331K-Sarm1 ${ }^{+-}$mice reduced significantly over time, indicating progressive, age-related axon degeneration due to TDP- $43^{\mathrm{Q}^{331 K}}$ expression. However, in Q331K-Sarm1 ${ }^{-/}$mice axon 
loss was significantly attenuated at all ages tested, and early fragmentation was reduced by $67 \%$ at 5 weeks when compared to Q331K-Sarm1 ${ }^{+/-}$mice $(p=0.0014)$ (Fig. 1e, f). We also assessed the diameter of remaining unfragmented YFP+ axons within the L4 ventral nerve root. At 10 months of age, the mean axon diameter was significantly reduced in the Q331K-Sarm1 ${ }^{+/-}$mice by $27 \%$ compared to NTG $(p<0.0001)$ (Fig. 1g), and this was partially attenuated in Q331K-Sarm1 $1^{-/-}$mice $(p=$ 0.0386) (Fig. 1h). Collectively, these results indicate that Sarm1 deletion partially protects motor axons from the neurodegenerative effects of human mutant TDP$43^{\mathrm{Q} 331 \mathrm{~K}}$.

\section{Sarm 1 deletion reduces TDP- $43^{\mathrm{Q} 331 \mathrm{~K}}$-mediated NMJ degeneration}

Previous studies have shown that deletion of Sarm1 preserves NMJ integrity for several days following peripheral nerve transection [55]. We therefore assessed whether Sarm1 deletion afforded similar protection against TDP-43 ${ }^{\mathrm{Q} 331 \mathrm{~K}}$-mediated NMJ degeneration (Fig. 2a-d). At 5 weeks of age NMJ innervation in gastrocnemius muscles of TDP- $43^{\mathrm{Q} 331 \mathrm{~K}}$ mice was considerably lower than in NTG mice, indicating that TDP- $43^{\mathrm{Q} 331 \mathrm{~K}}$ causes very early and severe denervation $(p<0.0001)$ (Fig. 2b). Innervation patterns were comparable between Q331K-Sarm1 $1^{+-}$and Q331K-Sarm1 $1^{-/-}$mice at 5 weeks of age, but at 3 months of age Q331K-Sarm1 ${ }^{-/-}$mice demonstrated $45 \%$ fewer denervated NMJs $(p=0.0124)$ and $58 \%$ more fully-innervated NMJs $(p=0.0032)$ than Q331K-Sarm1 ${ }^{+/-}$mice (Fig. 2b, c). By 10 months of age the percentage of denervated NMJs was still significantly reduced in Q331K-Sarm1 ${ }^{-/-}$mice compared to Q331KSarm $1^{+/-}$mice $(p=0.0030)$, and there was a trend towards an increase in partially innervated NM)s ( $p=$ 0.0711) (Fig. 2d). To determine if these improvements in $\mathrm{NMJ}$ innervation influenced muscle bulk, gastrocnemius muscle weights were compared. Male TDP- $43^{\mathrm{Q} 331 \mathrm{~K}}$ mice as young as 5 weeks of age showed significant muscle weight loss, which progressed with age (Additional file 1a). In

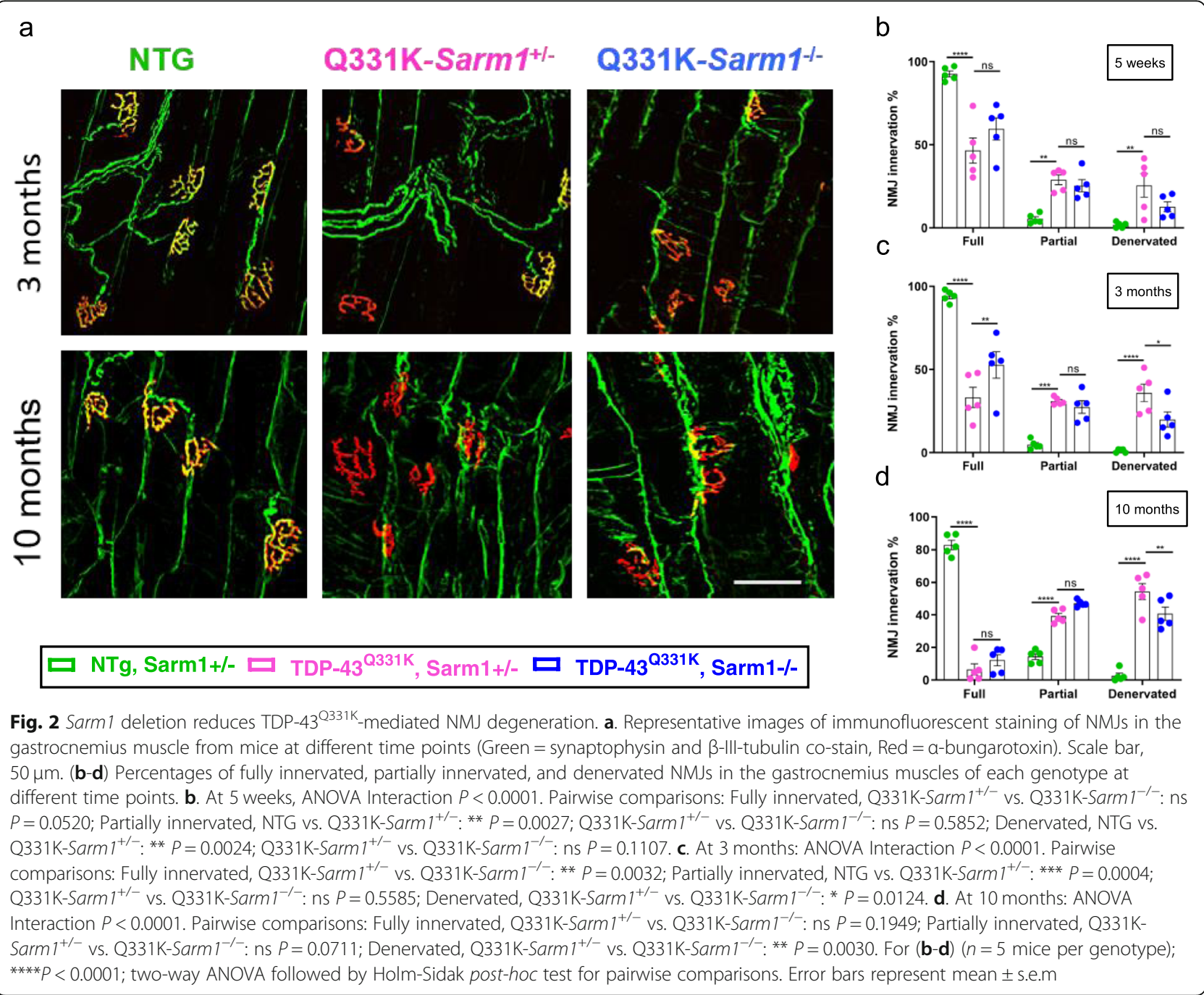


females, significant muscle loss was only observed in TDP$43^{\mathrm{Q} 331 \mathrm{~K}}$ mice at 15 months of age (Additional file $1 \mathrm{~b}$ ). However, no significant differences in muscle weight were seen between Q331K-Sarm1 ${ }^{+/-}$and Q331K-Sarm1 $1^{-/-}$mice, indicating that the improvement in NMJ innervation due to Sarm1 deletion was not enough to influence muscle atrophy caused by TDP $-43^{\mathrm{Q} 331 \mathrm{~K}}$.

\section{TDP- $43^{\mathrm{Q} 331 \mathrm{~K}}$-mediated cerebral atrophy and cortical} neuronal loss are not suppressed by Sarm 1 deletion ALS overlaps clinically, pathologically and genetically with FTD, which is characterised by atrophy of the temporal as well as the frontal lobes of the brain. We therefore examined the brains of our mice to determine if TDP- $43^{\mathrm{Q} 331 \mathrm{~K}}$ overexpression and/or Sarm1 play a role in neurodegeneration of cerebral structures. An examination of whole brains from both male and female mice was performed. This demonstrated a significant loss of brain mass in male Q331K-Sarm1 $1^{+/-}$and Q331KSarm $1^{-/}$mice compared to NTG from early timepoints (6\% at 5 weeks, $5 \%$ at 3 months, and $8 \%$ at 10 months of age, Fig. 3a). Significant brain weight loss in females was only seen at 15 months of age (Fig. 3b). No significant differences were seen between Q331K-Sarm1 ${ }^{+/-}$and Q331K-Sarm $1^{-/-}$mice, suggesting that Sarm1 deletion does not suppress gross brain atrophy secondary to $\mathrm{TDP}-43^{\mathrm{Q} 331 \mathrm{~K}}$. However, measuring total brain weights may not be a sensitive enough method to find subtle differences in brain weight, and cannot be used to identify regional volume loss. We therefore conducted an ex vivo, in loco brain magnetic resonance imaging (MRI) study in a separate group of female mice. This analysis confirmed that both the Q331K-Sarm1 ${ }^{+/-}\left(505 \pm 4 \mathrm{~mm}^{3}\right)$ and Q331K-Sarm1 ${ }^{-/-}$mice $\left(508 \pm 3 \mathrm{~mm}^{3}\right)$, had significantly smaller brains than the NTG mice $\left(534 \pm 5 \mathrm{~mm}^{3}\right)$, and also found no significant difference in total brain volumes between Q331K-Sarm1 ${ }^{+/-}$and Q331KSarm $1^{-1-}$ mice (Fig. 3c).

Further analyses of the MRI data were performed to identify region-specific effects of TDP- $43^{\mathrm{Q} 331 \mathrm{~K}}$ and Sarm1 deletion by measuring regional brain volumes and diffusivity parameters (Fractional Anisotropy (FA) and mean diffusivity (MD)) (Fig. 3d, e, Additional file 2a,b, Additional file 5: Table S1). We observed prominent decreases in regional brain volumes primarily located in temporal-equivalent and hippocampal regions of the brain, which were accompanied by much smaller changes in FA and no significant effects on MD (Fig. 3d, e, Additional file 5: Table S1). A Region of Interest (ROI) analysis compared in more detail the changes in volume and FA in specific brain regions as outlined in the DSURQE mouse atlas (Additional file 5: Table S1). Significantly reduced volume was observed in several areas including the insular region (6.77\%), dorsolateral entorhinal cortex (11.65\%), perirhinal cortex (14.04\%), amygdala (9.7\%), hippocampal CA3 (6.69\%), and pre-para subiculum $(7.77 \%)$ in Q331K$\mathrm{Sarm}^{+/-}$mice compared to NTG mice. This indicates that the greatest brain volume loss occurred preferentially in temporal lobe-equivalent regions of TDP- $43^{\mathrm{Q}^{3} 31 \mathrm{~K}}$ mice (Additional file 2a). Decreased FA was observed in several white matter tracts including the anterior commissure $(4.1 \%)$, stria terminalis $(3.2 \%)$ internal capsule $(1.1 \%)$ and facial nerve $(3.5 \%)$, while several grey matter temporal regions showed an increase in FA including the ectorhinal cortex $(2.11 \%)$, perirhinal cortex (1.68\%), and insular region (3.00\%) in Q331KSarm1 ${ }^{+/-}$mice (Additional file 5: Table S1). Overall, however, there were no significant regional differences in brain volume or FA between Q331K-Sarm1 $1^{+/-}$and Q331K$\mathrm{Sarm}^{-/-}$mice (Additional file 2b).

To investigate the cellular cause of the changes observed with MRI in TDP-43 ${ }^{\mathrm{Q} 331 \mathrm{~K}}$ mice, YFP-expressing neurons in the cortex were counted. Neuronal numbers were significantly decreased $(p=0.0009)$ in the entorhinal cortex of Q331K-Sarm1 $1^{+/-}$mice, which contrasts with no significant loss of neurons in the motor cortex (Fig. 3f, g). Neuron numbers were not significantly different between Q331K-Sarm1 ${ }^{+/-}$and Q331K-Sarm1 ${ }^{-/-}$ mice in either brain region. Collectively, these studies demonstrate that Sarm1 deletion does not influence regional brain atrophy or neuronal loss caused by TDP$43^{\mathrm{Q} 331 \mathrm{~K}}$, and that temporal-lobe equivalent brain regions are more significantly affected by TDP- $43^{\mathrm{Q} 331 \mathrm{~K}}$ overexpression than the primary motor cortex.

\section{TDP- $43^{\mathrm{Q} 331 \mathrm{~K}}$-mediated dendritic spine defects in the motor cortex are suppressed by Sarm 1 deletion}

Synaptic degeneration and dendritic spine loss are an early feature of neurodegenerative conditions including dementias [32]. TDP-43 plays a crucial role in the formation and turnover of dendritic spines, as manipulation of TDP-43 expression causes significant changes in spine morphology and density in cortical neurons [21, 29, 33]. SARM1 also regulates synaptic plasticity and dendritic spine growth $[11,43]$. Although our studies of the brain demonstrated that TDP- $43^{\mathrm{Q}^{331} \mathrm{~K}}$-induced cortical atrophy and neuronal loss were not suppressed by Sarm1 deletion, we hypothesised that Sarm1 deletion could still mitigate dendritic spine loss in mutant mice. We therefore examined spine density and shape in layer $\mathrm{V}$ of the motor cortex in TDP- $43^{\mathrm{Q} 331 \mathrm{~K}}$ and NTG mice, focussing specifically on distal branches of apical dendrites, as they form abundant arbours rich in spines (Fig. 4a). TDP$43^{\mathrm{Q} 331 \mathrm{~K}}$ expression reduced spine density to only $45 \%$ that of NTG mice $(p=0.0014)$ but this was significantly improved in Q331K-Sarm1 ${ }^{-1-}$ mice to $78 \%$ of NTG ( $p=$ 
0.0268) (Fig. 4b). Analyses of individual spine volume and surface area demonstrated no significant differences between any genotypes (Additional file 3a,b). Morphologically, dendritic spines can be classified into three main subsets: thin, stubby, and mushroom [34, 68]. While thin spines are usually transient with a rapid turnover, mature stubby and mushroom spines establish stable connections $[9,35]$. To determine if the alterations in dendritic spine densities were associated with specific morphological subsets, we calculated the density of thin, stubby, or mushroom shaped spines (Fig. 4c-e). The density of thin spines in Q331K-Sarm ${ }^{+/-}$mice was reduced to $38 \%$ that of NTG mice $(p=0.0034)$, while stubby and mature spines were not significantly altered. However, Q331K-Sarm1 ${ }^{-/}$mice demonstrated a higher density of thin spines, reaching $81 \%$ of the density seen in NTG mice $(p=0.0227)$. Collectively, these results indicate that Sarm1 deletion significantly suppresses

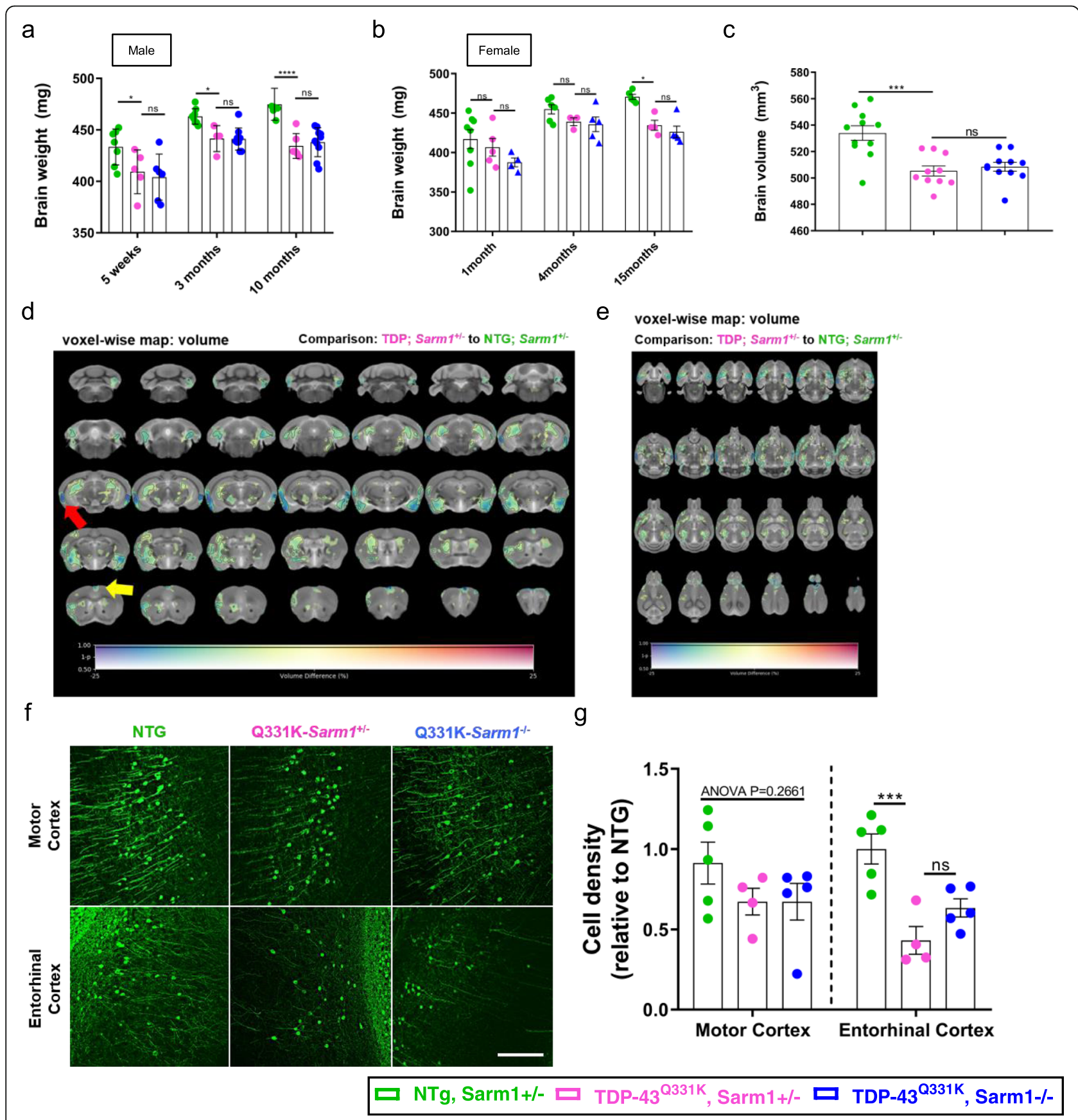

Fig. 3 (See legend on next page.) 


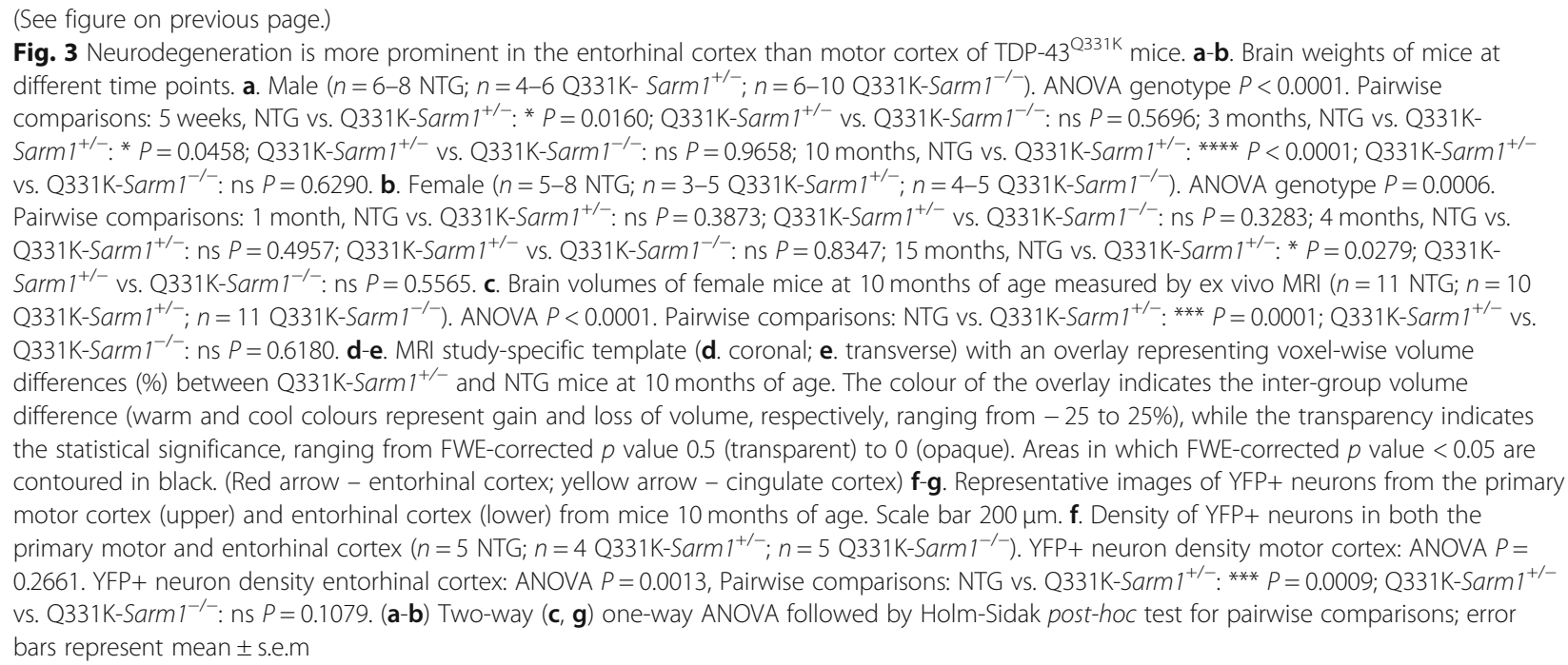

dendritic spine loss caused by TDP-43 ${ }^{\mathrm{Q} 331 \mathrm{~K}}$, preferentially maintaining a population of thin spines.

\section{Sarm 1 deletion attenuates the pre-weaning loss of male TDP-43 ${ }^{\text {Q331K }}$ mice but does not influence age-related behavioural impairments}

Having determined that Sarm1 deletion ameliorated TDP-43 $3^{\text {Q331K }}$-induced motor neuron degeneration and dendritic spine loss we bred larger cohorts of mice for behavioural studies. During breeding we found that female mice surviving to at least 10 days of age were present at Mendelian ratios (Fig. 5a). However, fewer males survived to this age carrying the TDP $-43^{\mathrm{Q} 331 \mathrm{~K}}$ transgene than would be expected by Mendelian inheritance laws $(44 \%, 54 / 124)$. In contrast, a higher-than-expected proportion of male mice survived that were Sarm1 $1^{-1-}(61 \%, 76 / 124)$, and more specifically, a significant majority $(63 \%, 34 / 54)$ of males with a TDP-43 transgene were $\mathrm{Sarm}^{-/-}$. This suggests that successful embryonic and/or early post-natal development of male offspring is inhibited by TDP- $43^{\mathrm{Q} 331 \mathrm{~K}}$ overexpression, and that this effect is mitigated by Sarm1 deletion.

To determine if Sarm1 signalling contributes to behavioural deficits caused by TDP- $43^{\mathrm{Q} 331 \mathrm{~K}}$ motor function was assayed using Rotarod. From 3 months of age all male TDP- $43^{\mathrm{Q} 331 \mathrm{~K}}$ mice demonstrated a progressive decline in motor performance compared to their NTG littermates, however, no significant difference was seen between Q331K-Sarm1 $1^{-/-}$and Q331K-Sarm1 $1^{+/-}$mice (Fig. 5b). Interestingly, TDP-43 ${ }^{\mathrm{Q} 331 \mathrm{~K}}$ mice gained significantly more weight than NTG littermates from as early as 3 months of age. Again, no significant difference was seen between Q331K-Sarm1 $1^{-/-}$and Q331K-Sarm1 ${ }^{+/-}$ male mice (Fig. 5c). Similar observations were made in female mice (Additional file $4 a, b$ ). Given that weight gain is likely to impair Rotarod performance, weight-independent motor deficits in males were measured by hindlimb clasping, which is thought to be a measure of spastic motor impairment $[36,86]$. From 3 months of age, greater clasping was observed in TDP- $43^{\mathrm{Q} 331 \mathrm{~K}}$ compared to NTG mice with no difference seen between Q331K-Sarm1 $1^{-/-}$and Q331K-Sarm1 ${ }^{+/-}$mice (Fig. 5d). To examine cognitive function we used the marble-burying assay, a measure of innate digging behaviour [74, 82]. Up to 7 months of age, NTG mice buried over $75 \%$ of marbles. However, Q331K-Sarm1 ${ }^{+/-}$mice demonstrated significantly attenuated digging behaviour with only $\sim 25 \%$ of marbles being buried from as early as 3 months of age, and declining further by 7 months of age, indicating striking cognitive impairment (Fig. 5e). This deficit was not reversed by Sarm1 deletion. Collectively, these results indicate that TDP- $43^{\mathrm{Q} 331 \mathrm{~K}}$ causes early and prominent changes in weight, motor and cognitive performance, which are not attenuated by Sarm1 deletion.

\section{Discussion}

Here, we have shown that by deleting Sarm1 from a TDP-43 ${ }^{\text {Q331K }}$ transgenic mouse model of ALS-FTD it is possible to significantly attenuate motor axon, NMJ and motor neuron cell body degeneration. Sarm1 deletion appeared to protect motor neuron cell bodies to a greater extent than motor axons, which were in turn protected more so than NMJs (compare Fig. 1c, e and 2c). An underlying mechanism for this could be that motor neurons are reliant on neurotrophic support from distal targets of innervation for continued survival $[59,64,76]$. By preserving the physical link between the cell body and the target muscle, Sarm1 deletion may improve cell body survival by helping to maintain retrograde trophic support. 


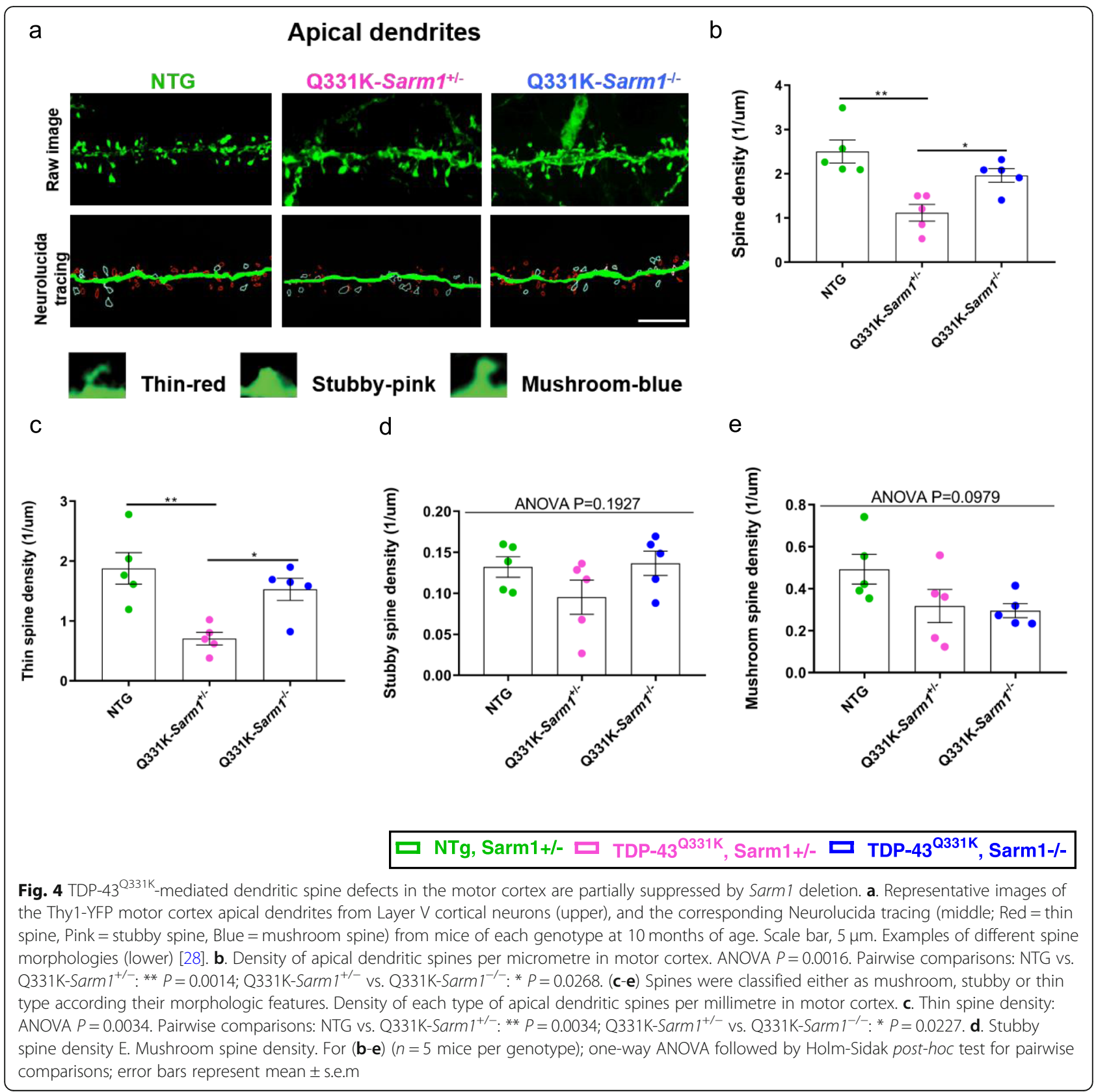

Collectively, these findings are in keeping with the hypothesis that ALS is a dying-back disease in which the most distal compartments of motor neurons (the NMJs and axons) are the most vulnerable in disease.

Importantly, our study design used Sarm1 hemizygosity to enable comparison with littermate controls without the need for an excessively large breeding program. The inability of Sarm1 hemizygosity to preserve severed sciatic nerves for up to 2 weeks supports this approach. However, it cannot be ruled out that Sarm1 hemizygosity is partially protective in some circumstances. This raises the possibility that in the present study we may be underestimating the protective capacity of Sarm1 deletion as we did not utilise mice that were $\operatorname{Sarm}^{+/+}$as controls.

This study used a TDP- $43^{\mathrm{Q} 331 \mathrm{~K}}$ transgenic mouse previously described as a model of ALS [4]. Interestingly, we observed several characteristics that were not previously reported for this model and which are reminiscent of FTD. We noted that TDP-43 ${ }^{\mathrm{Q} 331 \mathrm{~K}}$ mice gained significant weight compared to NTG mice. Mutants were also strikingly cognitively impaired and demonstrated 


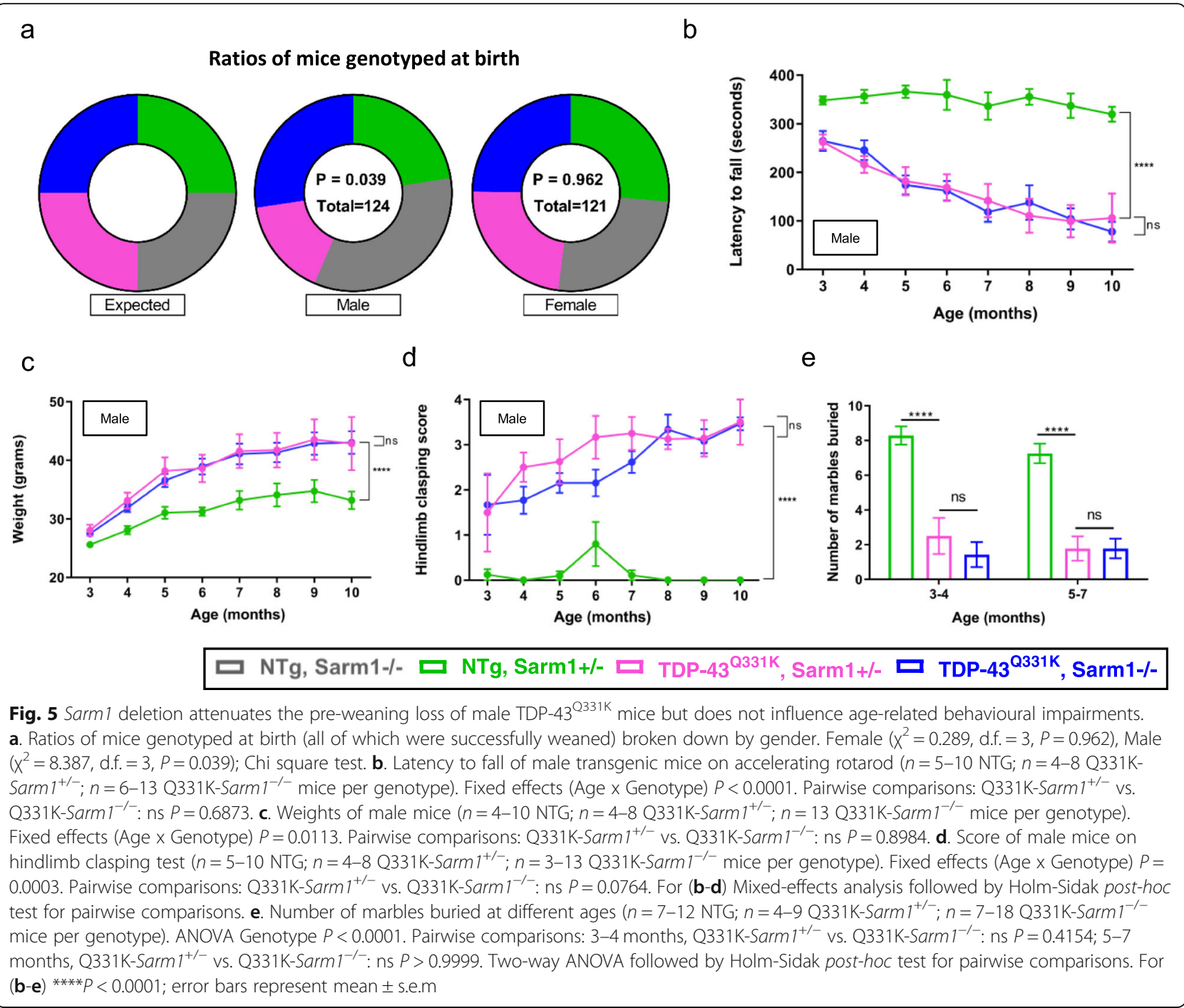

significant brain atrophy from an early stage. No weight gain or cognitive dysfunction was previously described in this mouse model [4]. These differences could be because mice bred for this study were on a different background to that previously described. Although food intake was not measured, the excessive weight gain that mutants displayed could be due to hyperphagia, which is a feature of human FTD, and which we previously described in TDP- $43^{\mathrm{Q} 331 \mathrm{~K}}$ knock-in mice [82]. It also remains possible that this weight gain is due to direct effects of TDP-43 overexpression on lipid metabolism [12, 70].

In keeping with findings in humans, MRI demonstrated prominent brain atrophy in areas corresponding to the temporal lobe in these mice, and we histologically corroborated a greater neuronal loss in the entorhinal cortex than in the motor cortex. This is interesting, because studies in humans have shown that the temporal lobe can be significantly affected in ALS patients even without clinical evidence of dementia or temporal lobe- specific dysfunction (Loewe et al. Sci Rep 2017). While this study found no evidence of changes in MD, decreased FA was detected in several white matter tracts further matching the tractography findings in human patients [56]. Small but significant increases in FA in the temporal grey matter regions that also feature volume loss are difficult to interpret, but may be linked to a combination of alterations in glial and fibre density [71]. Collectively, these observations suggest that this TDP$43^{\mathrm{Q} 331 \mathrm{~K}}$ transgenic mouse recapitulates features of FTD as well as ALS.

Of particular relevance to FTD, mutant TDP-43 has previously been shown to cause cortical dendritic spine abnormalities that are associated with attenuated neuronal transmission [21, 29]. In keeping with this, our study revealed significant brain atrophy and dendritic spine loss in TDP- $43^{\mathrm{Q} 331 \mathrm{~K}}$ mice. Furthermore, our study is the first to demonstrate that this dendritic spine degeneration can be mitigated by deletion of Sarm1. 
This is notable as Wallerian and Wallerian-like degeneration has only previously been linked with axonal, NMJ and post-synaptic integrity. Our results now suggest that Wallerian pathways are relevant to post-synaptic compartments of neurons, although it is also possible that the increase in dendritic spines following Sarm1 deletion is secondary to the preservation of presynaptic nerve terminals that synapse onto the spines.

Interestingly, TDP- $43^{\mathrm{Q} 331 \mathrm{~K}}$ overexpression phenotypes show evidence of sexual divergence. This comes from the observation that during breeding, mutant mice were underrepresented amongst males but not females. This is in keeping with our previous observations in TDP- $43^{\mathrm{Q} 331 \mathrm{~K}}$ knock-in mice, in which mutant males but not females were present at a lower frequency than would be expected by Mendelian laws of inheritance [82]. These phenomena are also more generally consistent with the higher incidence of ALS in male patients $[48,75]$. Furthermore, we also found that amongst males there were significantly more Q331K-Sarm1 ${ }^{-/-}$mice than Q331K-Sarm1 $1^{+/}$mice (Fig. 1b). This suggests that TDP- $43^{\mathrm{Q} 331 \mathrm{~K}}$ influences nervous system development in a way that is attenuated by Sarm1 deletion. We speculate that this beneficial effect of Sarm1 deletion may occur in utero by influencing Wallerian-like degeneration in a manner similar to that observed during the rescue of CNS nerve tracts and peripheral nerve axons in embryos lacking Nmnat2 [26].

Despite the suppression of neurodegeneration by Sarm1 deletion, this was insufficient to cause behavioural improvements in TDP- $43^{\mathrm{Q} 331 \mathrm{~K}}$ overexpressing mice. This could be because this mouse model demonstrated very early and marked brain and muscle atrophy, which may be difficult to reverse. A similar explanation may underlie the apparent lack of efficacy of Sarm1 deletion in a mutant SOD1 mouse model of ALS, which demonstrates rapid disease onset and progression [57], and in our previous study in Drosophila in which even clonal TDP-43 ${ }^{\mathrm{Q} 331 \mathrm{~K}}$ overexpression causes early and aggressive neurodegeneration [69]. We speculate that under less extreme degrees of cellular disintegration, and in more physiological models, which are likely to be more reflective of early disease states in patients with ALS-FTD, Sarm1 deletion may have a greater ability to attenuate behavioural and motor dysfunction. Further support of this comes from human genome-wide studies that have identified an association between genetic variants at the human SARM1 locus and the risk of developing ALS [22]. It remains to be determined if these genetic variants influence SARM1 expression, but if so then this would further support a mechanistic link between TDP-43-mediated toxicity in sporadic ALS and Wallerian-like degeneration.

\section{Conclusions}

In conclusion, our results indicate that a Sarm1 dependent pathway contributes to TDP- $43^{\mathrm{Q} 331 \mathrm{~K}}$-mediated motor neuron, motor axon, NMJ and cortical spine degeneration in vivo. Anti-SARM1 therapies therefore have potential as a treatment for diseases of the ALSFTD spectrum.

\section{Additional files}

Additional file 1: Gastrocnemius muscle weights in male and female mice. (PDF 720 kb)

Additional file 2: Additional MRI data. (PDF $4210 \mathrm{~kb}$ )

Additional file 3: Dendritic spine morphology in motor cortex. (PDF $459 \mathrm{~kb}$ ) Additional file 4: Behavioural characterisation of female mice. (PDF $747 \mathrm{~kb}$ ) Additional file 5: Table S1. Results of ROI analyses of volume and FA changes in different brain 121 regions comparing the mean of each genotype with that of every other group. (PDF $602 \mathrm{~kb}$ )

\section{Abbreviations}

ALS: Amyotrophic lateral sclerosis; FTD: Frontotemporal dementia; NAD: Nicotinamide adenine dinucleotide; Nmnat: Nicotinamide mononucleotide adenylyltransferase; Sarm 1: Sterile alpha and TIR motifcontaining protein 1; SNP: Single nucleotide polymorphism; TDP-43: TAR DNA-binding protein 43; WId $\mathrm{W}^{5}$ : Wallerian degeneration slow

\section{Acknowledgements}

We thank Babraham Institute Experimental Unit staff for technical assistance, Dr. George Chennell of the Wohl Cellular Imaging Centre at Maurice Wohl Clinical Neuroscience Institute, King's College London for imaging assistance, and members of M.P.C.'s laboratory, J.-M. Gallo, and A.C. Vernon for helpful discussions.

\section{Authors' contributions}

MW conducted behavioural studies and harvested tissues. JS performed genotyping and harvested tissues. ZL, MW, EPA, CH, CKH, EB, IC, HBW, AL conducted histological studies. EK, DC, CS acquired MRI data and analysed data. RM, MPC, JS supervised studies. ZL, MW and JS wrote the manuscript. All authors read and approved the final manuscript.

\section{Funding}

J. Sreedharan gratefully acknowledges support from the Motor Neuron Disease Association, the Medical Research Council UK, the Lady Edith Wolfson Fellowship Fund, the van Geest Foundation, the Rosetrees Trust, Alzheimer's Research UK, and the Psychiatry Research Trust. M.P.C is supported by the van Geest Foundation. We gratefully acknowledge the Chinese Scholarship Council for supporting Ziqiang Lin during this study.

Availability of data and materials

The authors will make all data available to readers upon reasonable request.

\section{Ethics approval}

All animal experiments were performed under the UK animals (Scientific Procedures) Act 1986 Amendment Regulations 2012.

\section{Consent for publication}

Not applicable.

\section{Competing interests}

The authors declare that they have no competing interests.

\section{Author details}

'Department of Basic and Clinical Neuroscience, The Maurice Wohl Clinical Neuroscience Institute, Institute of Psychiatry, Psychology and Neuroscience (loPPN), King's College London, London SE5 9RT, UK. 'West China School of Medicine, West China Hospital, Sichuan University, Chengdu, China. ${ }^{3}$ BRAIN 
Centre (Biomarker Research And Imaging for Neuroscience), Department of Neuroimaging, loPPN, King's College London, London, UK. ${ }^{4}$ Division of Systems Medicine, School of Medicine, University of Dundee, Dundee, Scotland, UK. John van Geest Centre for Brain Repair, Department of Clinical Neurosciences, University of Cambridge, Cambridge, UK. ${ }^{6}$ Department of Neuroscience, Sheffield Institute for Translational Neuroscience, University of Sheffield, Sheffield, UK. ${ }^{7}$ Signalling Programme, Babraham Institute, Babraham Research Campus, Cambridge, UK.

\section{Received: 22 July 2019 Accepted: 30 August 2019}

-

\section{References}

1. Adalbert R, Nogradi A, Babetto E, Janeckova L, Walker SA, Kerschensteiner M, Misgeld T, Coleman MP (2009) Severely dystrophic axons at amyloid plaques remain continuous and connected to viable cell bodies. Brain 132: 402-416. https://doi.org/10.1093/brain/awn312

2. Altaf MA, Sreedharan, Charyulu N (2008) lonic gelation controlled drug delivery systems for gastric-mucoadhesive microcapsules of captopril. Indian J Pharm Sci 70:655-658. https://doi.org/10.4103/0250-474X.45410

3. Arai T, Hasegawa M, Akiyama H, Ikeda K, Nonaka T, Mori H, Mann D, Tsuchiya K, Yoshida M, Hashizume $Y$ et al (2006) TDP-43 is a component of ubiquitin-positive tau-negative inclusions in frontotemporal lobar degeneration and amyotrophic lateral sclerosis. Biochem Biophys Res Commun 351:602-611. https://doi.org/10.1016/j.bbrc.2006.10.093

4. Arnold ES, Ling SC, Huelga SC, Lagier-Tourenne C, Polymenidou M, Ditsworth D, Kordasiewicz HB, McAlonis-Downes M, Platoshyn O, Parone PA et al (2013) ALS-linked TDP-43 mutations produce aberrant RNA splicing and adult-onset motor neuron disease without aggregation or loss of nuclear TDP-43. Proc Natl Acad Sci U S A 110:E736-E745. https://doi.org/10. 1073/pnas.1222809110

5. Beirowski B, Babetto E, Coleman MP, Martin KR (2008) The WIdS gene delays axonal but not somatic degeneration in a rat glaucoma model. Eur $\mathrm{J}$ Neurosci 28:1166-1179. https://doi.org/10.1111/j.1460-9568.2008.06426.x

6. Beirowski B, Berek L, Adalbert R, Wagner D, Grumme DS, Addicks K, Ribchester RR, Coleman MP (2004) Quantitative and qualitative analysis of Wallerian degeneration using restricted axonal labelling in YFP-H mice. J Neurosci Methods 134:23-35. https://doi.org/10.1016/j.jneumeth.2003.10.016

7. Benajiba L, Le Ber I, Camuzat A, Lacoste M, Thomas-Anterion C, Couratier P, Legallic S, Salachas F, Hannequin D, Decousus M et al (2009) TARDBP mutations in motoneuron disease with frontotemporal lobar degeneration. Ann Neurol 65:470-473. https://doi.org/10.1002/ana.21612

8. Blair IP, Williams KL, Warraich ST, Durnall JC, Thoeng AD, Manavis J, Blumbergs PC, Vucic S, Kiernan MC, Nicholson GA (2010) FUS mutations in amyotrophic lateral sclerosis: clinical, pathological, neurophysiological and genetic analysis. J Neurol Neurosurg Psychiatry 81:639-645. https://doi.org/ 10.1136/jnnp.2009.194399

9. Bourne J, Harris KM (2007) Do thin spines learn to be mushroom spines that remember? Curr Opin Neurobiol 17:381-386. https://doi.org/10.1016/j.conb. 2007.04.009

10. Braak H, Ludolph A, Thal DR, Del Tredici K (2010) Amyotrophic lateral sclerosis: dash-like accumulation of phosphorylated TDP-43 in somatodendritic and axonal compartments of somatomotor neurons of the lower brainstem and spinal cord. Acta Neuropathol 120:67-74. https://doi. org/10.1007/s00401-010-0683-0

11. Chen CY, Lin CW, Chang CY, Jiang ST, Hsueh YP (2011) Sarm1, a negative regulator of innate immunity, interacts with syndecan-2 and regulates neuronal morphology. J Cell Biol 193:769-784. https://doi.org/10.1083/jcb. 201008050

12. Chiang PM, Ling J, Jeong YH, Price DL, Aja SM, Wong PC (2010) Deletion of TDP-43 down-regulates Tbc1 11, a gene linked to obesity, and alters body fat metabolism. Proc Natl Acad Sci U S A 107:16320-16324. https://doi.org/ 10.1073/pnas.1002176107

13. Conforti L, Gilley J, Coleman MP (2014) Wallerian degeneration: an emerging axon death pathway linking injury and disease. Nat Rev Neurosci 15:394-409. https://doi.org/10.1038/nrn3680

14. De Vos KJ, Grierson AJ, Ackerley S, Miller CC (2008) Role of axonal transport in neurodegenerative diseases. Annu Rev Neurosci 31:151-173. https://doi. org/10.1146/annurev.neuro.31.061307.090711

15. Delisle MB, Carpenter S (1984) Neurofibrillary axonal swellings and amyotrophic lateral sclerosis. J Neurol Sci 63:241-250
16. Estes PS, Boehringer A, Zwick R, Tang JE, Grigsby B, Zarnescu DC (2011) Wild-type and A315T mutant TDP-43 exert differential neurotoxicity in a Drosophila model of ALS. Hum Mol Genet 20:2308-2321. https://doi.org/10. 1093/hmg/ddr124

17. Feng G, Mellor RH, Bernstein M, Keller-Peck C, Nguyen QT, Wallace M, Nerbonne JM, Lichtman JW, Sanes JR (2000) Imaging neuronal subsets in transgenic mice expressing multiple spectral variants of GFP. Neuron 28:41-51

18. Ferri A, Sanes JR, Coleman MP, Cunningham JM, Kato AC (2003) Inhibiting axon degeneration and synapse loss attenuates apoptosis and disease progression in a mouse model of motoneuron disease. Curr Biol 13:669-673

19. Fischer LR, Culver DG, Davis AA, Tennant P, Wang M, Coleman M, Asress S, Adalbert R, Alexander GM, Glass JD (2005) The WldS gene modestly prolongs survival in the SOD1G93A fALS mouse. Neurobiol Dis 19:293-300. https://doi.org/10.1016/j.nbd.2005.01.008

20. Fischer LR, Culver DG, Tennant P, Davis AA, Wang M, Castellano-Sanchez A, Khan J, Polak MA, Glass JD (2004) Amyotrophic lateral sclerosis is a distal axonopathy: evidence in mice and man. Exp Neurol 185:232-240

21. Fogarty MJ, Klenowski PM, Lee JD, Drieberg-Thompson JR, Bartlett SE, Ngo ST, Hilliard MA, Bellingham MC, Noakes PG (2016) Cortical synaptic and dendritic spine abnormalities in a presymptomatic TDP-43 model of amyotrophic lateral sclerosis. Sci Rep 6:37968. https://doi.org/10.1038/ srep37968

22. Fogh I, Ratti A, Gellera C, Lin K, Tiloca C, Moskvina V, Corrado L, Soraru G, Cereda C, Corti Set al (2014) A genome-wide association meta-analysis identifies a novel locus at 17q11.2 associated with sporadic amyotrophic lateral sclerosis. Hum Mol Genet 23: 2220-2231 Doi https://doi.org/10.1093/ $\mathrm{hmg} / \mathrm{ddt} 587$

23. Geisler S, Doan RA, Strickland A, Huang X, Milbrandt J, DiAntonio A (2016) Prevention of vincristine-induced peripheral neuropathy by genetic deletion of SARM1 in mice. Brain 139:3092-3108. https://doi.org/10.1093/brain/ aww251

24. Gerdts J, Summers DW, Sasaki Y, DiAntonio A, Milbrandt J (2013) Sarm1mediated axon degeneration requires both SAM and TIR interactions. J Neurosci 33:13569-13580. https://doi.org/10.1523/JNEUROSCI.1197-13.2013

25. Gilley J, Coleman MP (2010) Endogenous Nmnat2 is an essential survival factor for maintenance of healthy axons. PLoS Biol 8:e1000300. https://doi. org/10.1371/journal.pbio.1000300

26. Gilley J, Orsomando G, Nascimento-Ferreira I, Coleman MP (2015) Absence of SARM1 rescues development and survival of NMNAT2-deficient axons. Cell Rep 10:1974-1981. https://doi.org/10.1016/j.celrep.2015.02.060

27. Gilley J, Ribchester RR, Coleman MP (2017) Sarm1 deletion, but not WId(S), confers lifelong Rescue in a Mouse Model of severe Axonopathy. Cell Rep 21:10-16. https://doi.org/10.1016/j.celrep.2017.09.027

28. Handley EE, Pitman KA, Dawkins E, Young KM, Clark RM, Jiang TC, Turner BJ, Dickson TC, Blizzard CA (2016) Synapse dysfunction of layer V pyramidal neurons precedes neurodegeneration in a mouse model of TDP-43 Proteinopathies. Cereb Cortex. https://doi.org/10.1093/cercor/bhw185

29. Handley EE, Pitman KA, Dawkins E, Young KM, Clark RM, Jiang TC, Turner BJ, Dickson TC, Blizzard CA (2017) Synapse dysfunction of layer V pyramidal neurons precedes neurodegeneration in a mouse model of TDP-43 Proteinopathies. Cereb Cortex 27:3630-3647. https://doi.org/10.1093/cercor/ bhw185

30. Harris KM, Jensen FE, Tsao B (1992) Three-dimensional structure of dendritic spines and synapses in rat hippocampus (CA1) at postnatal day 15 and adult ages: implications for the maturation of synaptic physiology and longterm potentiation. J Neurosci 12:2685-2705

31. Henninger N, Bouley J, Sikoglu EM, An J, Moore CM, King JA, Bowser R, Freeman MR, Brown RH Jr (2016) Attenuated traumatic axonal injury and improved functional outcome after traumatic brain injury in mice lacking Sarm1. Brain 139:1094-1105. https://doi.org/10.1093/brain/aww001

32. Henstridge CM, Sideris DI, Carroll E, Rotariu S, Salomonsson S, Tzioras M, McKenzie CA, Smith C, von Arnim CAF, Ludolph AC et al (2018) Synapse loss in the prefrontal cortex is associated with cognitive decline in amyotrophic lateral sclerosis. Acta Neuropathol 135:213-226. https://doi.org/ 10.1007/s00401-017-1797-4

33. Herzog JJ, Deshpande M, Shapiro L, Rodal AA, Paradis S (2017) TDP-43 misexpression causes defects in dendritic growth. Sci Rep 7:15656. https:// doi.org/10.1038/s41598-017-15914-4

34. Holtmaat AJ, Trachtenberg JT, Wilbrecht L, Shepherd GM, Zhang X, Knott GW, Svoboda K (2005) Transient and persistent dendritic spines in the neocortex in vivo. Neuron 45:279-291. https://doi.org/10.1016/..neuron.2005.01.003 
35. Honkura N, Matsuzaki M, Noguchi J, Ellis-Davies GC, Kasai H (2008) The subspine organization of actin fibers regulates the structure and plasticity of dendritic spines. Neuron 57:719-729. https://doi.org/10. 1016/j.neuron.2008.01.013

36. Igaz LM, Kwong LK, Lee EB, Chen-Plotkin A, Swanson E, Unger T, Malunda J, Xu Y, Winton MJ, Trojanowski JQ et al (2011) Dysregulation of the ALSassociated gene TDP-43 leads to neuronal death and degeneration in mice. J Clin Invest 121:726-738. https://doi.org/10.1172/JCl44867

37. Ince PG, Shaw PJ, Slade JY, Jones C, Hudgson P (1996) Familial amyotrophic lateral sclerosis with a mutation in exon 4 of the $\mathrm{cu} / \mathrm{Zn}$ superoxide dismutase gene: pathological and immunocytochemical changes. Acta Neuropathol 92:395-403

38. Kabashi E, Lin L, Tradewell ML, Dion PA, Bercier V, Bourgouin P, Rochefort D, Bel Hadj S, Durham HD, Vande Velde C et al (2010) Gain and loss of function of ALS-related mutations of TARDBP (TDP-43) cause motor deficits in vivo. Hum Mol Genet 19:671-683. https://doi.org/10.1093/hmg/ddp534

39. Kabashi E, Valdmanis PN, Dion P, Spiegelman D, McConkey BJ, Vande Velde C, Bouchard JP, Lacomblez L, Pochigaeva K, Salachas F et al (2008) TARDBP mutations in individuals with sporadic and familial amyotrophic lateral sclerosis. Nat Genet 40:572-574. https://doi.org/10.1038/ng.132

40. Klim JR, Williams LA, Limone F, Guerra San Juan I, Davis-Dusenbery BN, Mordes DA, Burberry A, Steinbaugh MJ, Gamage KK, Kirchner R et al (2019) ALS-implicated protein TDP-43 sustains levels of STMN2, a mediator of motor neuron growth and repair. Nat Neurosci 22:167-179. https://doi.org/ 10.1038/s41593-018-0300-4

41. Laird AS, Van Hoecke A, De Muynck L, Timmers M, Van den Bosch L, Van Damme P, Robberecht W (2010) Progranulin is neurotrophic in vivo and protects against a mutant TDP-43 induced axonopathy. PLoS One 5:e13368. https://doi.org/10.1371/journal.pone.0013368

42. Li Y, Ray P, Rao EJ, Shi C, Guo W, Chen X, Woodruff EA 3rd, Fushimi K, Wu JY (2010) A Drosophila model for TDP-43 proteinopathy. Proc Natl Acad Sci U S A 107:3169-3174. https://doi.org/10.1073/pnas.0913602107

43. Lin CW, Chen CY, Cheng SJ, Hu HT, Hsueh YP (2014) Sarm1 deficiency impairs synaptic function and leads to behavioral deficits, which can be ameliorated by an mGluR allosteric modulator. Front Cell Neurosci 8:87. https://doi.org/10.3389/fncel.2014.00087

44. Lin MJ, Cheng CW, Shen CK (2011) Neuronal function and dysfunction of Drosophila dTDP. PLoS One 6:e20371. https://doi.org/10.1371/journal. pone.0020371

45. Loreto A, Di Stefano M, Gering M, Conforti L (2015) Wallerian degeneration is executed by an NMN-SARM1-dependent late ca(2+) influx but only modestly influenced by mitochondria. Cell Rep 13:2539-2552. https://doi. org/10.1016/j.celrep.2015.11.032

46. Lunn ER, Perry VH, Brown MC, Rosen H, Gordon S (1989) Absence of Wallerian degeneration does not hinder regeneration in peripheral nerve. Eur J Neurosci 1:27-33

47. Mack TG, Reiner M, Beirowski B, Mi W, Emanuelli M, Wagner D, Thomson D, Gillingwater T, Court F, Conforti L et al (2001) Wallerian degeneration of injured axons and synapses is delayed by a Ube4b/Nmnat chimeric gene. Nat Neurosci 4:1199-1206. https://doi.org/10.1038/nn770

48. Manjaly ZR, Scott KM, Abhinav K, Wijesekera L, Ganesalingam J, Goldstein LH, Janssen A, Dougherty A, Willey E, Stanton BR et al (2010) The sex ratio in amyotrophic lateral sclerosis: a population based study. Amyotroph Lateral Scler 11:439-442. https://doi.org/10.3109/17482961003610853

49. Melamed Z, Lopez-Erauskin J, Baughn MW, Zhang O, Drenner K, Sun Y, Freyermuth F, McMahon MA, Beccari MS, Artates JW et al (2019) Premature polyadenylation-mediated loss of stathmin-2 is a hallmark of TDP-43dependent neurodegeneration. Nat Neurosci 22:180-190. https://doi.org/10. 1038/s41593-018-0293-z

50. Moisse K, Volkening K, Leystra-Lantz C, Welch I, Hill T, Strong MJ (2009) Divergent patterns of cytosolic TDP-43 and neuronal progranulin expression following axotomy: implications for TDP-43 in the physiological response to neuronal injury. Brain Res 1249:202-211. https://doi.org/10.1016/j.brainres. 2008.10.021

51. Neukomm LJ, Burdett TC, Seeds AM, Hampel S, Coutinho-Budd JC, Farley JE, Wong J, Karadeniz YB, Osterloh JM, Sheehan AE et al (2017) Axon death pathways converge on Axundead to promote functional and structural axon disassembly. Neuron 95:78-91 e75. https://doi.org/10.1016/j.neuron. 2017.06.031

52. Neumann M, Sampathu DM, Kwong LK, Truax AC, Micsenyi MC, Chou T, Bruce J, Schuck T, Grossman M, Clark CM et al (2006) Ubiquitinated TDP-43 in frontotemporal lobar degeneration and amyotrophic lateral sclerosis. Science 314:130-133. https://doi.org/10.1126/science.1134108

53. Okamoto K, Hirai S, Shoji M, Senoh Y, Yamazaki T (1990) Axonal swellings in the corticospinal tracts in amyotrophic lateral sclerosis. Acta Neuropathol 80:222-226

54. Orlacchio A, Babalini C, Borreca A, Patrono C, Massa R, Basaran S, Munhoz RP, Rogaeva EA, St George-Hyslop PH, Bernardi G et al (2010) SPATACSIN mutations cause autosomal recessive juvenile amyotrophic lateral sclerosis. Brain 133:591-598. https://doi.org/10.1093/brain/awp325

55. Osterloh JM, Yang J, Rooney TM, Fox AN, Adalbert R, Powell EH, Sheehan $A E$, Avery MA, Hackett R, Logan MA et al (2012) dSarm/Sarm1 is required for activation of an injury-induced axon death pathway. Science 337:481-484. https://doi.org/10.1126/science.1223899

56. Panman JL, Jiskoot LC, Bouts M, Meeter LHH, van der Ende EL, Poos JM, Feis RA, Kievit AJA, van Minkelen R, Dopper EGP et al (2019) Gray and white matter changes in presymptomatic genetic frontotemporal dementia: a longitudinal MRI study. Neurobiol Aging 76:115-124. https://doi.org/10. 1016/j.neurobiolaging.2018.12.017

57. Peters OM, Lewis EA, Osterloh JM, Weiss A, Salameh JS, Metterville J, Brown RH, Freeman MR (2018) Loss of Sarm1 does not suppress motor neuron degeneration in the SOD1G93A mouse model of amyotrophic lateral sclerosis. Hum Mol Genet 27:3761-3771. https://doi.org/10.1093/ hmg/ddy260

58. Pun S, Santos AF, Saxena S, Xu L, Caroni P (2006) Selective vulnerability and pruning of phasic motoneuron axons in motoneuron disease alleviated by CNTF. Nat Neurosci 9:408-419. https://doi.org/10.1038/nn1653

59. Rogers M-L (2014) Neurotrophic therapy for ALS/MND. In: Kostrzewa RM (ed) Handbook of neurotoxicity. Springer, New York, City, pp 1755-1785

60. Sajadi A, Schneider BL, Aebischer P (2004) Wlds-mediated protection of dopaminergic fibers in an animal model of Parkinson disease. Curr Biol 14: 326-330. https://doi.org/10.1016/j.cub.2004.01.053

61. Samsam M, Mi W, Wessig C, Zielasek J, Toyka KV, Coleman MP, Martini R (2003) The Wlds mutation delays robust loss of motor and sensory axons in a genetic model for myelin-related axonopathy. J Neurosci 23:2833-2839

62. Sasaki S, Takeda T, Shibata N, Kobayashi M (2010) Alterations in subcellular localization of TDP-43 immunoreactivity in the anterior horns in sporadic amyotrophic lateral sclerosis. Neurosci Lett 478:72-76. https://doi.org/10. 1016/j.neulet.2010.04.068

63. Sato T, Takeuchi S, Saito A, Ding W, Bamba H, Matsuura H, Hisa Y, Tooyama I, Urushitani M (2009) Axonal ligation induces transient redistribution of TDP-43 in brainstem motor neurons. Neuroscience 164:1565-1578. https:// doi.org/10.1016/j.neuroscience.2009.09.050

64. Schaller S, Buttigieg D, Alory A, Jacquier A, Barad M, Merchant M, Gentien D, de la Grange P, Haase G (2017) Novel combinatorial screening identifies neurotrophic factors for selective classes of motor neurons. Proc Natl Acad Sci U S A 114:E2486-E2493. https://doi.org/10.1073/pnas.1615372114

65. Shan X, Chiang PM, Price DL, Wong PC (2010) Altered distributions of Gemini of coiled bodies and mitochondria in motor neurons of TDP-43 transgenic mice. Proc Natl Acad Sci U S A 107:16325-16330. https://doi.org/ 10.1073/pnas.1003459107

66. Shin JE, Miller BR, Babetto E, Cho Y, Sasaki Y, Qayum S, Russler EV, Cavalli V, Milbrandt J, DiAntonio A (2012) SCG10 is a JNK target in the axonal degeneration pathway. Proc Natl Acad Sci U S A 109:E3696-E3705. https:// doi.org/10.1073/pnas.1216204109

67. Smith EF, Shaw PJ, De Vos KJ (2017) The role of mitochondria in amyotrophic lateral sclerosis. Neurosci Lett. https://doi.org/10.1016/j.neulet. 2017.06.052

68. Spruston N (2008) Pyramidal neurons: dendritic structure and synaptic integration. Nat Rev Neurosci 9:206-221. https://doi.org/10.1038/nrn2286

69. Sreedharan J, Neukomm LJ, Brown RH Jr, Freeman MR (2015) Agedependent TDP-43-mediated motor neuron degeneration requires GSK3, hat-trick, and xmas-2. Curr Biol: Doi. https://doi.org/10.1016/j.cub.2015.06.045

70. Stallings NR, Puttaparthi K, Dowling KJ, Luther CM, Burns DK, Davis K, Elliott IL (2013) TDP-43, an ALS linked protein, regulates fat deposition and glucose homeostasis. PLoS One 8:e71793. https://doi.org/10.1371/journal. pone.0071793

71. Stolp HB, Ball G, So PW, Tournier JD, Jones M, Thornton C, Edwards AD (2018) Voxel-wise comparisons of cellular microstructure and diffusion-MR in mouse hippocampus using 3D bridging of optically-clear histology with neuroimaging data (3D-BOND). Sci Rep 8:4011. https://doi.org/10.1038/ s41598-018-22295-9 
72. Summers DW, DiAntonio A, Milbrandt J (2014) Mitochondrial dysfunction induces Sarm1-dependent cell death in sensory neurons. J Neurosci 34: 9338-9350. https://doi.org/10.1523/JNEUROSCI.0877-14.2014

73. Swarup V, Phaneuf D, Bareil C, Robertson J, Rouleau GA, Kriz J, Julien JP (2011) Pathological hallmarks of amyotrophic lateral sclerosis/ frontotemporal lobar degeneration in transgenic mice produced with TDP43 genomic fragments. Brain 134:2610-2626. https://doi.org/10.1093/brain/ awr159

74. Thomas A, Burant A, Bui N, Graham D, Yuva-Paylor LA, Paylor R (2009) Marble burying reflects a repetitive and perseverative behavior more than novelty-induced anxiety. Psychopharmacology 204:361-373. https://doi.org/ 10.1007/s00213-009-1466-y

75. Tollefsen E, Midgren B, Bakke P, Fondenes O (2010) Amyotrophic lateral sclerosis: gender differences in the use of mechanical ventilation. Eur J Neurol 17:1352-1357. https://doi.org/10.1111/j.1468-1331.2010.03036.x

76. Tovar YRLB, Ramirez-Jarquin UN, Lazo-Gomez R, Tapia R (2014) Trophic factors as modulators of motor neuron physiology and survival: implications for ALS therapy. Front Cell Neurosci 8:61. https://doi.org/10 3389/fncel.2014.00061

77. Vande Velde C, Garcia ML, Yin X, Trapp BD, Cleveland DW (2004) The neuroprotective factor WIds does not attenuate mutant SOD1-mediated motor neuron disease. NeuroMolecular Med 5:193-203. https://doi.org/10 1385/NMM:5:3:193

78. Veriepe J, Fossouo L, Parker JA (2015) Neurodegeneration in C. elegans models of ALS requires TIR-1/Sarm 1 immune pathway activation in neurons Nat Commun 6:7319. https://doi.org/10.1038/ncomms8319

79. Walker LJ, Summers DW, Sasaki Y, Brace EJ, Milbrandt J, DiAntonio A (2017) MAPK signaling promotes axonal degeneration by speeding the turnover of the axonal maintenance factor NMNAT2. Elife 6. https://doi. org/10.7554/eLife.22540

80. Waller AV (1850) Experiments on the section of the glossopharyngeal and hypoglossal nerves of the frog, and observations of the alterations produced thereby in the structure of their primitive fibres. Philos Trans 140. https://doi.org/10.1098/rstl.1850.0021

81. Wegorzewska I, Bell S, Cairns NJ, Miller TM, Baloh RH (2009) TDP-43 mutant transgenic mice develop features of ALS and frontotemporal lobar degeneration. Proc Natl Acad Sci U S A 106:18809-18814. https://doi.org/10. 1073/pnas.0908767106

82. White MA, Kim E, Duffy A, Adalbert R, Phillips BU, Peters OM, Stephenson J, Yang S, Massenzio F, Lin Z et al (2018) TDP-43 gains function due to perturbed autoregulation in a Tardbp knock-in mouse model of ALS-FTD. Nat Neurosci 21:552-563. https://doi.org/10.1038/s41593-018-0113-5

83. Xiao S, McLean J, Robertson J (2006) Neuronal intermediate filaments and ALS: a new look at an old question. Biochim Biophys Acta 1762:1001-1012

84. Xiong X, Hao Y, Sun K, Li J, Li X, Mishra B, Soppina P, Wu C, Hume Rl, Collins CA (2012) The Highwire ubiquitin ligase promotes axonal degeneration by tuning levels of Nmnat protein. PLoS Biol 10:e1001440. https://doi.org/10. 1371/journal.pbio.1001440

85. Xu YF, Zhang YJ, Lin WL, Cao X, Stetler C, Dickson DW, Lewis J, Petrucelli $L$ (2011) Expression of mutant TDP-43 induces neuronal dysfunction in transgenic mice. Mol Neurodegener 6:73. https://doi.org/ 10.1186/1750-1326-6-73

86. Yazawa I, Giasson BI, Sasaki R, Zhang B, Joyce S, Uryu K, Trojanowski JQ, Lee VM (2005) Mouse model of multiple system atrophy alpha-synuclein expression in oligodendrocytes causes glial and neuronal degeneration. Neuron 45:847-859. https://doi.org/10.1016/j.neuron.2005.01.032

87. Zhou H, Huang C, Chen H, Wang D, Landel CP, Xia PY, Bowser R, Liu YJ, Xia XG (2010) Transgenic rat model of neurodegeneration caused by mutation in the TDP gene. PLoS Genet 6:e1000887. https://doi.org/10.1371/journal. pgen.1000887

\section{Publisher's Note}

Springer Nature remains neutral with regard to jurisdictional claims in published maps and institutional affiliations.

Ready to submit your research? Choose BMC and benefit from:

- fast, convenient online submission

- thorough peer review by experienced researchers in your field

- rapid publication on acceptance

- support for research data, including large and complex data types

- gold Open Access which fosters wider collaboration and increased citations

- maximum visibility for your research: over $100 \mathrm{M}$ website views per year

At BMC, research is always in progress.

Learn more biomedcentral.com/submissions 